\title{
Experimental and Theoretical Studies on Regiocontrol of Benzyne Reactions Using Silyl and Boryl Directing Groups
}

\author{
Takashi Ikawa, ${ }^{1}$ Hiroaki Tokiwa, ${ }^{2}$ and Shuji Akai ${ }^{1, *}$ \\ ${ }^{1}$ School of Pharmaceutical Sciences, University of Shizuoka \\ 52-1 Yada, Suruga-ku, Shizuoka 422-8526, Japan \\ ${ }^{2}$ Department of Chemistry, Faculty of Science, Rikkyo University \\ 3-34-1 Nishi-ikebukuro, Toshima-ku, Tokyo 171-8501
}

(Received August 3, 2012; E-mail: akai@u-shizuoka-ken.ac.jp)

\begin{abstract}
The silyl- and boryl-directed regiocontrol of benzyne reactions and their theoretical analyses using density functional theory (DFT) are described herein. The Diels-Alder reactions of both 3-silyl- and 3-borylbenzynes with substituted furans and the [3+2] cycloadditions of 3-silylbenzynes with 1,3-dipoles predominantly produced distal cycloadducts, whereas the [3+2] cycloadditions of the borylbenzynes exclusively produced proximal cycloadducts. Moreover, primary amines selectively underwent nucleophilic addition reactions at the more hindered ortho-position of the silyl group of the benzynes. The origin of these anomalous regiochemistries was theoretically evaluated using the natural bond orbital and reaction pathway analyses including the transition states of these reactions. On the basis of DFT calculations, it is proposed that the reactions of the borylbenzynes were controlled by the electrostatic effect of the boryl group, whereas those of the silylbenzynes were primarily governed by the steric effect of the silyl group.
\end{abstract}

\section{Introduction}

$o$-Benzyne, which is formally generated by the abstraction of two adjacent hydrogen atoms from benzene, has been long known as one of the most important reaction intermediates in organic synthesis and has been extensively studied. ${ }^{1}$ Although the existence of this molecule as a highly reactive intermediate was a mere speculation around a century ago, ${ }^{2}$ its existence was later confirmed, ${ }^{3}$ and then, it has been proven to be isolable in a matrix at low temperature. ${ }^{4}$ The distortion of the triple bond in the six-membered ring system of benzyne triggers its distinctive reactions, among which the Diels-Alder (DA) reactions have been extensively utilized to build benzo-fused ring systems in single steps. ${ }^{1}$ Since the development of the fluorideion-mediated mild preparation of benzyne from $o$-(trimethylsilyl)phenyl triflate by Kobayashi and co-workers, ${ }^{5}$ a wide variety of unprecedented benzyne reactions, such as transition-metal-catalyzed reactions, ${ }^{1 \mathrm{~b}}$ insertion reactions, ${ }^{1}$ and multi-component coupling reactions, ${ }^{\text {lc }}$ have been developed (Figure 1). ${ }^{1}$ Therefore, it is clear that benzyne chemistry is now in another rapidly developing era and has been attracting the interest of synthetic, organometallic, bioorganic, and medicinal chemists.

Benzyne chemistry has nevertheless been plagued by a serious long-recognized problem in that the reactions of unsymmetrically substituted benzynes generally produce mixtures of two possible regioisomers in varying ratios. For example, the DA reactions ${ }^{6}$ of benzynes appended with an alkyl $\left(\mathrm{R}^{1}=\mathrm{Me}, t-\right.$ $\mathrm{Bu}$, Table 1 , entries 5 and 6$),{ }^{7 \mathrm{a}, \mathrm{b}}$ a carbamoyl $\left(\mathrm{R}^{1}=\mathrm{CONEt}_{2}\right.$, entry 7$),{ }^{7 \mathrm{c}}$ or a nitro group $\left(\mathrm{R}^{1}=\mathrm{NO}_{2} \text {, entry } 8\right)^{7 \mathrm{~g}}$ at the 3 position provided mixtures of the proximal and distal adducts in varying ratios, and their regioselectivities were hardly predictable, although those having inductively electron-withdrawing groups, such as fluoro $\left(\mathrm{R}^{1}=\mathrm{F} \text {, entries } 1 \text { and } 2\right)^{7 \mathrm{~d}}$ and alkoxy groups $\left(\mathrm{R}^{1}=\mathrm{OMe}\right.$, entries 3 and 4$),{ }^{7 e, \mathrm{f}}$ produced cycloadducts with good-to-excellent proximal selectivities.

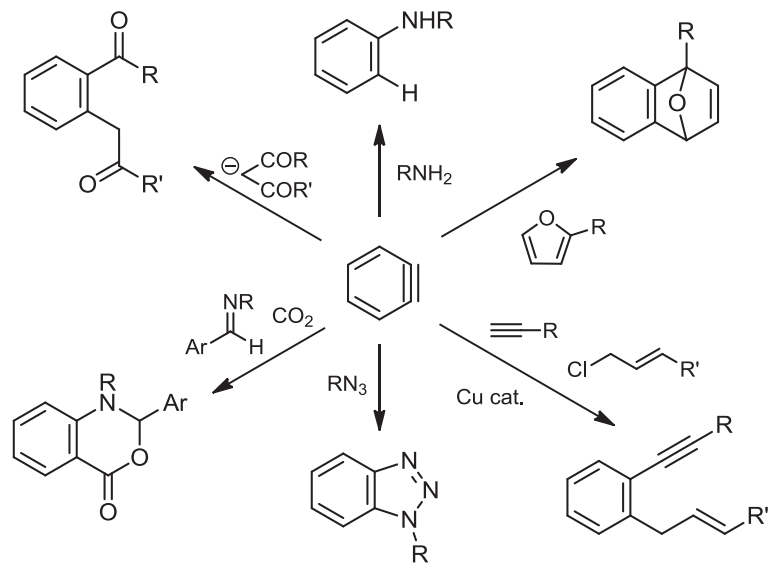

Figure 1. Various types of benzyne reactions.

Table 1. Regioselectivities in DA reactions of 3-substituted benzynes with furans.

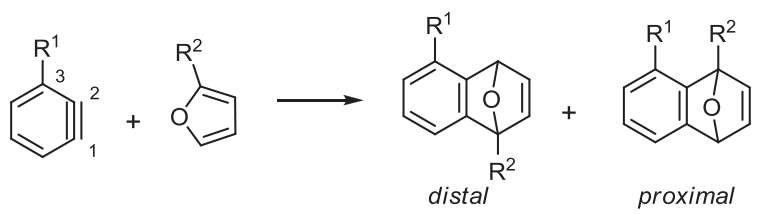

\begin{tabular}{cccccc}
\hline Entry & $\mathrm{R}^{1}$ & $\mathrm{R}^{2}$ & distal : proximal & Yield (\%) & Ref $^{a}$ \\
\hline 1 & $\mathrm{~F}$ & $\mathrm{Me}$ & $36: 64$ & 61 & $7 \mathrm{~d}$ \\
2 & $\mathrm{~F}$ & $t$-Bu & $10: 90$ & 59 & $7 \mathrm{~d}$ \\
3 & $\mathrm{OMe}$ & $t-\mathrm{Bu}$ & $15: 85$ & 34 & $7 \mathrm{f}$ \\
4 & $\mathrm{OMe}$ & $\mathrm{OMe}$ & $1:>99$ & 75 & $7 \mathrm{e}$ \\
5 & $\mathrm{Me}$ & $\mathrm{Me}$ & $42: 58$ & 74 & $7 \mathrm{~b}$ \\
6 & $t$-Bu $^{b}$ & $t-\mathrm{Bu}$ & $65: 35$ & 57 & $7 \mathrm{a}$ \\
7 & $\mathrm{CONEt}_{2}$ & $\mathrm{Me}$ & $50: 50$ & 60 & $7 \mathrm{c}$ \\
8 & $\mathrm{NO}_{2}$ & $\mathrm{Me}$ & $36: 64$ & 74 & $7 \mathrm{~g}$ \\
\hline
\end{tabular}

${ }^{a}$ Reference. ${ }^{b} 3,5-\mathrm{Di}($ tert-butyl)benzyne was used 
The use of semi-metallic silyl and boryl substituents as regio-directing groups has become one of the major tools in various reactions. ${ }^{8,9}$ In the case of benzyne reactions, Suzuki and $\mathrm{co}^{-}$-workers first reported the regioselective cycloaddition reactions of 3-silylbenzynes with nitrones. ${ }^{10,11}$ Herein, we present our very recent results on the regiocontrol of benzyne reactions using silyl ${ }^{12,13 a}$ and boryl groups. ${ }^{14,15}$ Given that the silyl and boryl substituents of the products can be converted into a variety of carbon-, oxygen-, and nitrogen-substituents, the current method provides a new and reliable alternative means of synthesizing multisubstituted aromatic compounds. The mechanism underlying the regioselective reactions of the silyl- and boryl-benzynes is also discussed herein based on DFT calculations.

\section{Experimental Results}

\subsection{Diels-Alder Reactions of 3-Silylbenzynes with Furans}

Based on our interest in the development of a new method of synthesizing 1-arylnaphthalenes and their derivatives, ${ }^{16}$ the DA reaction of 3-phenylbenzyne $\mathbf{5} \alpha$, generated in situ by the treatment of a precursor $1 \alpha$ with $n-\mathrm{BuLi}$ at $-78{ }^{\circ} \mathrm{C}$, and tertbutylfuran $4 \mathbf{a}$ was preliminarily investigated. The reaction gave rise to a mixture of two regioisomers, distal $-\mathbf{8} \alpha \mathbf{a}$ and proxi$m a l-8 \alpha \mathbf{a}$, in $70 \%$ total yield; however, the regioselectivity was quite low (distallproximal=43:57, Table 2, entry 1). Considering another of our experimental results (distal-9 $\beta \mathbf{a} /$ proximal$\mathbf{9} \beta \mathbf{a}=63: 37$, Table 2, entry 2) and other reports, ${ }^{17}$ it appears that simple steric bulkiness was largely ineffective for controlling the regiochemistry of the DA reaction of the benzynes.

The focus was subsequently turned to 3 -silylbenzynes ${ }^{10,11}$ as substrates for the synthesis of 1-arylnaphthalenes, given that the lower electronegativity of silicon relative to that of carbon (Allred-Rochow electronegativities, Si: 1.7, C: 2.5) should exert an electrostatic effect on the benzyne nucleus, thereby producing a distinction between $\mathrm{C} 1$ and $\mathrm{C} 2$, thus enabling control of the regiochemistry of the DA reaction. The possible transformation of the silyl groups to various aryl groups using Hiyama couplings ${ }^{18,19}$ was another motivating factor for examining the use of 3-silylbenzynes as new dienophiles for the DA reaction. Combination of the DA and

Table 2. DA reactions of benzynes 5-7 with 2-(tert-butyl)furan 4a.

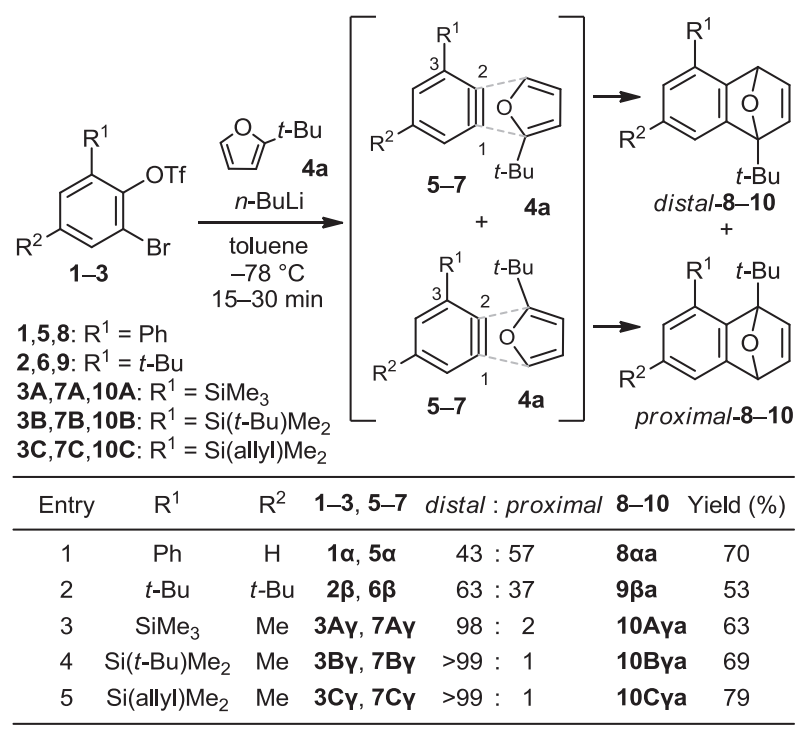

Hiyama reactions was expected to enable the regioselective synthesis of various 1-arylnaphthalenes and their derivatives.

The initial reaction of 3-(trimethylsilyl)benzyne 7A $\gamma$, generated in situ from the precursor $\mathbf{3 A} \gamma$ using $n-\mathrm{BuLi}$, and $\mathbf{4 a}$ predominantly generated the distal adduct distal-10A $\gamma \mathbf{a}$ along with proximal-10A $\gamma \mathbf{a}$ (distallproximal $=98: 2$ ) in $63 \%$ total yield (Table 2, entry 3). Similar reactions of 3-(tert-butyldimethylsilyl)benzyne $\mathbf{7 B} \gamma$ and 3-(allyldimethylsilyl)benzyne $\mathbf{7} \mathbf{C} \gamma$ respectively furnished distal-10B $\gamma \mathbf{a}$ and distal-10C $\gamma \mathbf{a}$ as exclusive products (entries 4 and 5). These data provide conclusive evidence that the silyl groups have an outstanding ability to effectively control the regioselectivity of benzyne reactions.

The scope and limitation of the distal selective DA reaction of variously substituted $\mathbf{7 B}$ or $\mathbf{7 C}$ and furans $\mathbf{4}$ were explored (Table 3). The ratios of distal-10B to proximal-10B and those of distal-10C to proximal-10C ranged from 71:29 to $>99: 1$, and the ratios were slightly affected by the substituents $\left(\mathrm{R}^{1}\right.$ and $\left.\mathrm{SiR}^{2} \mathrm{Me}_{2}\right)$ of $\mathbf{7 B}$ or $\mathbf{7 C}$. For example, the reaction of 3-(tert-butyldimethylsilyl)-5-methylbenzyne $7 \mathbf{B} \gamma\left(\mathrm{R}^{1}=\mathrm{Me}\right.$, $\left.\mathrm{R}^{2}=t-\mathrm{Bu}\right)$ with 2 -butylfuran $4 \mathrm{~b}\left(\mathrm{R}^{3}=n-\mathrm{Bu}, \mathrm{R}^{4}=\mathrm{H}\right)$ gave an $85: 15$ mixture of distal $-\mathbf{1 0 B} \gamma \mathbf{b}$ and proximal $-\mathbf{1 0 B} \gamma \mathbf{b}$, and the reaction of 3-(tert-butyldimethylsilyl)-5-fluorobenzyne $7 \mathbf{B} \delta$ $\left(\mathrm{R}^{1}=\mathrm{F}, \mathrm{R}^{2}=t-\mathrm{Bu}\right)$ provided $10 \mathrm{~B} \delta \mathbf{b}$ in a slightly higher ratio (distallproximal $=91: 9)$. On the other hand, the bulkier $\mathrm{R}^{3}$ group at the 2 position of $\mathbf{4}$ significantly improved the distal selectivity, and the $\mathrm{R}^{4}$ group at the 3 position of $4\left(\mathrm{R}^{3}=\mathrm{H}, \mathrm{R}^{4}\right.$ $=\mathrm{Me}$ ) also induced distal selectivity (for details, see Scheme 4). Various functional groups, such as fluoro, methoxy, (tetrahydropyranyl)oxy, trimethylsilyl, and tributylstannyl groups, were tolerated under the given reaction conditions.

In contrast, similar reactions of 4-methoxy-2-siloxyfuran $\mathbf{1 1}$ with $\mathbf{7 B}$ or $\mathbf{7 C}$ respectively generated proximal $-\mathbf{1 2 B}$ or $-\mathbf{1 2 C}$ as the predominant products. Because these adducts were

Table 3. DA reactions of 3-silylbenzynes (7B or 7C) with furans 4 .

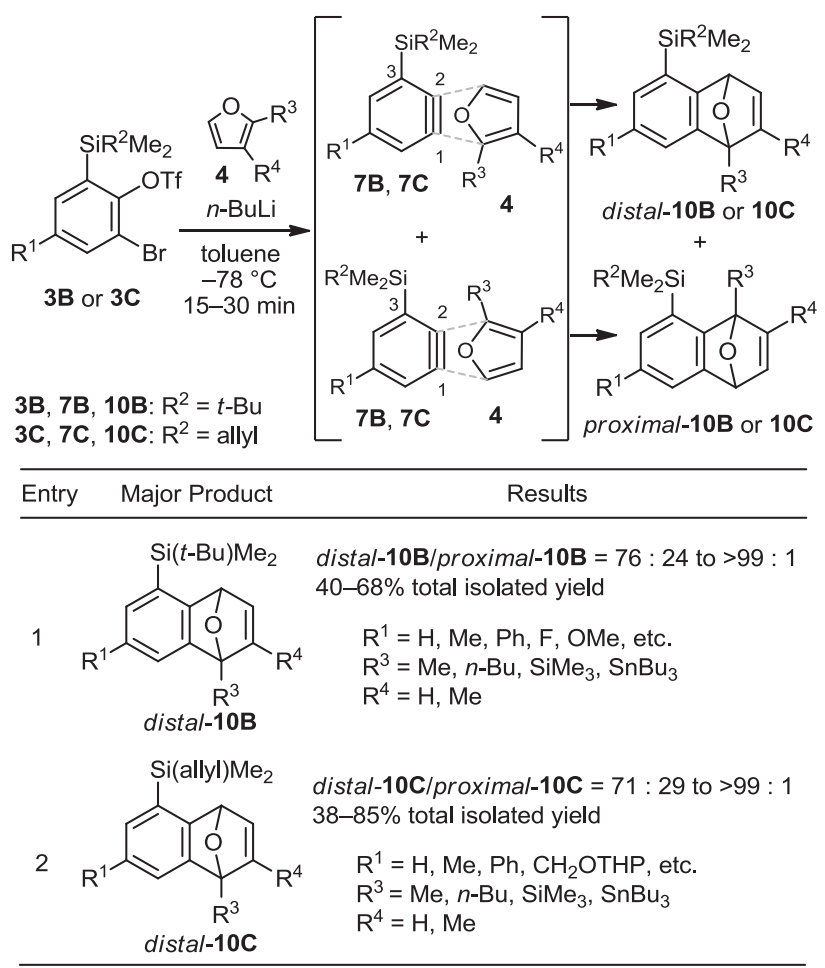


unstable in air under ambient conditions, the corresponding naphthoquinones (proximal-13B and -13C) and the acetate proximal-14B were obtained after the treatment of the crude products with either ceric ammonium nitrate $(\mathrm{CAN})$ or $\mathrm{Ac}_{2} \mathrm{O} /$ pyridine, respectively (Table 4 ). The proximal selectivities were excellent in all cases.

Table 4. DA reactions of 3-silylbenzynes (7B or 7C) with 4-alkoxy-2-siloxyfuran 11.
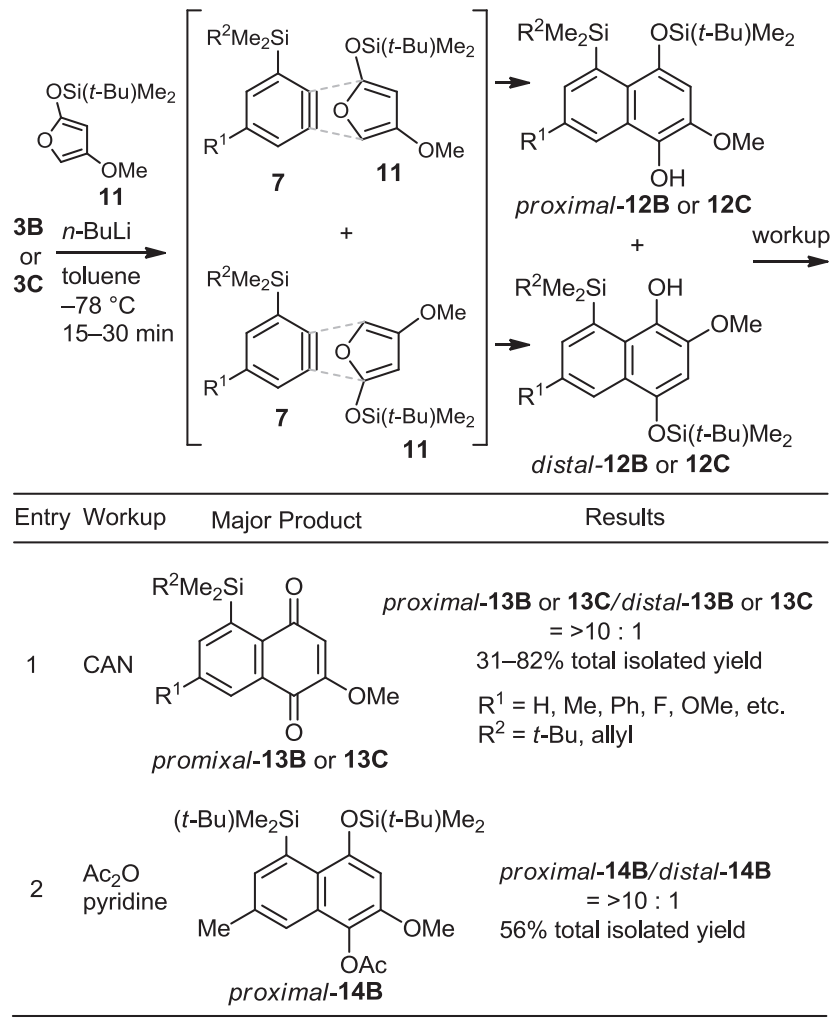

The Hiyama coupling of distal-10B with aryl iodides was achieved via intramolecular activation of the silyl group. ${ }^{20}$ Following the regioselective 1,4-epoxy-ring opening of distal10B using $\mathrm{TsOH}^{21}$ the phenolic hydroxyl groups were coordinated to the silicon atom at the peri-position under basic conditions, which promoted the coupling reactions with aryl iodides to give 1-arylnaphthalenes $\mathbf{1 6}$. Thus, the coupling reaction proceeded without the use of a fluoride ion (Scheme 1, Eq. 1). ${ }^{22}$ The fact that the silyl group was transferred to the neighboring oxygen atom during the reaction indicated the formation of pentacoordinate silicate intermediates. This is the first example of the Hiyama coupling using the robust (tertbutyldimethylsilyl)arenes. ${ }^{23}$

Other useful transformations of distal-10 for the synthesis of multisubstituted naphthalene derivatives are also shown in Scheme 1. The TMSI-promoted desilylation and epoxy-ring opening of distal-10B provided 1-naphthol 17 (Eq. 2). 1,8Dihydroxynaphthalenes $\mathbf{1 8},{ }^{24}$ which had previously been difficult to synthesize, were obtained by the Tamao oxidation ${ }^{25}$ of distal-10C, followed by the regioselective epoxy-ring opening (Eq. 3).

\subsection{Diels-Alder Reactions of 3-Borylbenzynes with Furans and Pyrroles}

The potential of boronic acids and boronates not only as synthetic intermediates $^{26}$ but also as functional molecules ${ }^{27}$
Scheme 1. Synthesis of substituted naphthalenes $\mathbf{1 6}-\mathbf{1 8}$ by transformations of distal-10B or $\mathbf{1 0 C}$.
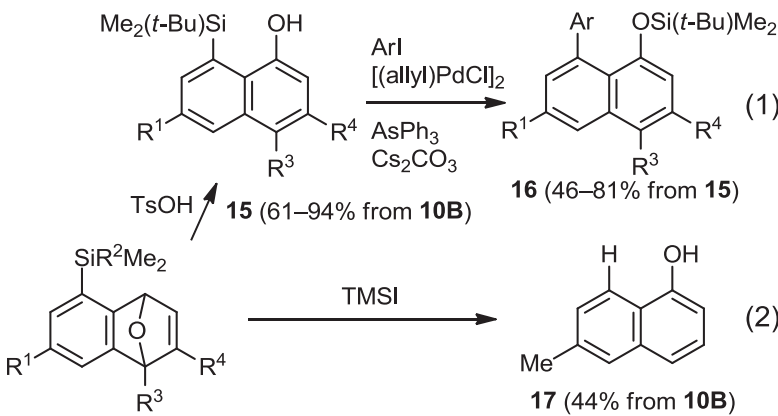

$$
\begin{aligned}
& \text { distal-10B }\left(\mathrm{R}^{2}=t-\mathrm{Bu}\right) \\
& \text { distal-10C }\left(\mathrm{R}^{2}=\text { allyl }\right) \\
& \text { 2) } \mathrm{TsOH} \\
& \text { 1) } \mathrm{H}_{2} \mathrm{O}_{2}, \mathrm{Bu}_{4} \mathrm{NF}
\end{aligned}
$$

and drug candidates has garnered significant attention. ${ }^{28}$ Thus, efficient synthetic protocols for generating aryl boronic acids have been sought by organic chemists. The approach to the novel synthesis of aryl boronates used by the authors was based on the construction of carbon frameworks from benzynes containing boronic functionalities. However, prior to the initiation of this project, there had been no prior reports of borylbenzynes.

Initially, the preparation of 3-silylbenzynes 7 was applied to the preparation of 3-borylbenzyne $\mathbf{2 1} \gamma\left(\mathrm{R}^{1}=\mathrm{Bpin}, \mathrm{R}^{2}=\mathrm{Me}\right)$, and its generation was evaluated by the DA reaction with $n^{-}$ butylfuran 4b. However, the use of various alkyllithiums resulted in low yields of the cycloadduct $\mathbf{2 2} \gamma \mathbf{b}\left(\mathrm{R}^{1}=\right.$ Bpin, $\mathrm{R}^{2}$ $=\mathrm{Me})$. Extensive trials revealed that the efficiency of $21 \alpha$ generation was significantly enhanced by the reaction of 2-boryl6-iodophenyl triflate $20 \alpha \quad\left(\mathrm{R}^{1}=\right.$ Bpin, $\left.\quad \mathrm{R}^{2}=\mathrm{H}\right) \quad$ with $i^{-}$ $\mathrm{PrMgCl} \cdot \mathrm{LiCl}^{29}$ in $\mathrm{Et}_{2} \mathrm{O}$ at $-78{ }^{\circ} \mathrm{C}$, which produced a $90: 10$ mixture of distal $-\mathbf{2 2} \alpha \mathbf{b}$ and proximal $-\mathbf{2 2} \alpha \mathbf{b}$ in $88 \%$ total yield (Table 5, entry 2). Such a high distal regioselectivity of the DA reaction of $\mathbf{2 1}$ was noteworthy considering that a similar reaction of tert-butylbenzyne $6 \gamma\left(\mathrm{R}^{1}=t-\mathrm{Bu}, \mathrm{R}^{1}=\mathrm{Me}\right)$ prepared

Table 5. DA reactions of benzynes (6 or 21) with $2-n$-butylfuran $\mathbf{4 b}$.

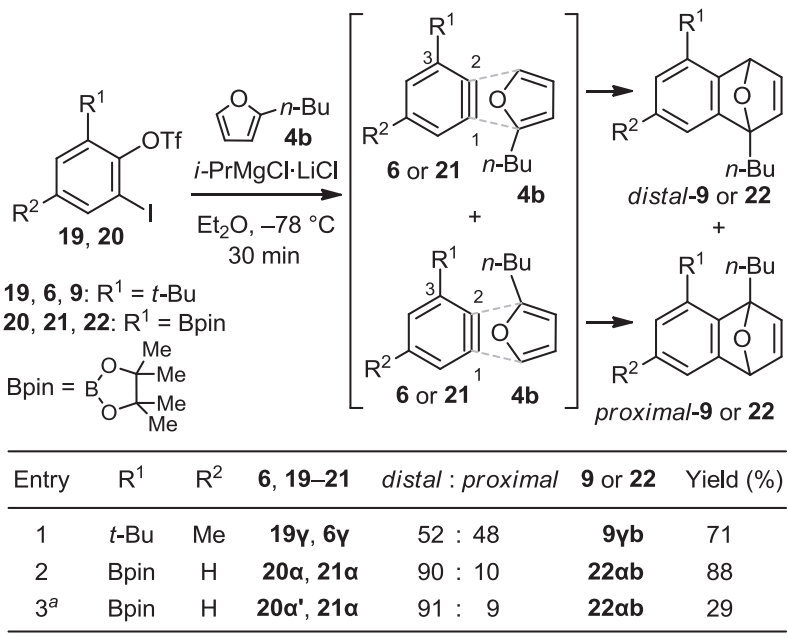

${ }^{a} \mathbf{2 0} \alpha$ ' was used instead of $\mathbf{2 0 \alpha}$. Bpin 20a' 
from $19 \gamma$ produced a 1:1 mixture of distal $-\mathbf{9} \gamma \mathbf{b}$ and proximal$\mathbf{9} \gamma \mathbf{b}$ (Table 5, entry 1). The use of an alternative precursor, $\mathbf{2 0} \alpha$, in which the positions of the iodo and sulfonyloxy groups were interchanged, generated a mixture of distal-22 $\alpha \mathbf{b}$ and proximal-22 $\alpha \mathbf{b}$ in the same ratio (distal-22 $\alpha \mathbf{b} /$ proximal$\mathbf{2 2} \alpha \mathbf{b}=91: 9$, entry 3 ) as that of entry 2, although the total yield of $\mathbf{2 2} \alpha \mathbf{b}$ was lower than that from $\mathbf{2 0} \alpha$. These results provided strong evidence to support the formation of the borylbenzyne $21 \alpha$.

The invention of the benzyne precursor $\mathbf{2 0}$ also offered the added benefit of facilitating the preparation of precursors with various labile functional groups without the use of strong bases such as $n$-BuLi. ${ }^{30}$ Thus, the DA reaction of various borylbenzynes 21, generated from 20, with 2-substituted furans $\mathbf{4}$ was investigated (Table 6). Under the optimized reaction conditions, the cycloaddition products $22(\mathrm{X}=\mathrm{O})$ were produced in 40-99\% yields with high distal selectivities (distal-22/proximal-22=82:18 to $>99: 1$, entry 1 ). Substituents such as ester, acyl, cyano, and bromo groups, were compatible under the reaction conditions. Surprisingly, the reaction of $\mathbf{4}$ appended with either an electron-withdrawing $\left(\mathrm{R}^{2}=\mathrm{CO}_{2} \mathrm{Me}\right)$ or an electron-donating $\left(\mathrm{R}^{2}=\mathrm{OMe}\right)$ group at the 2 position resulted in similar distal selectivities (entry 1). Similar reactions with $\mathrm{N}^{-}$ protected pyrroles 23 also produced cycloadducts $\mathbf{2 4}$, in which the distal adducts were again major products (entry 2). These results represented the first examples of regioselective DA reactions of substituted benzynes and pyrroles $23{ }^{31}$

Table 6. DA reaction of 3-borylbenzynes 21 with furans $\mathbf{4}$ or pyrroles 23.

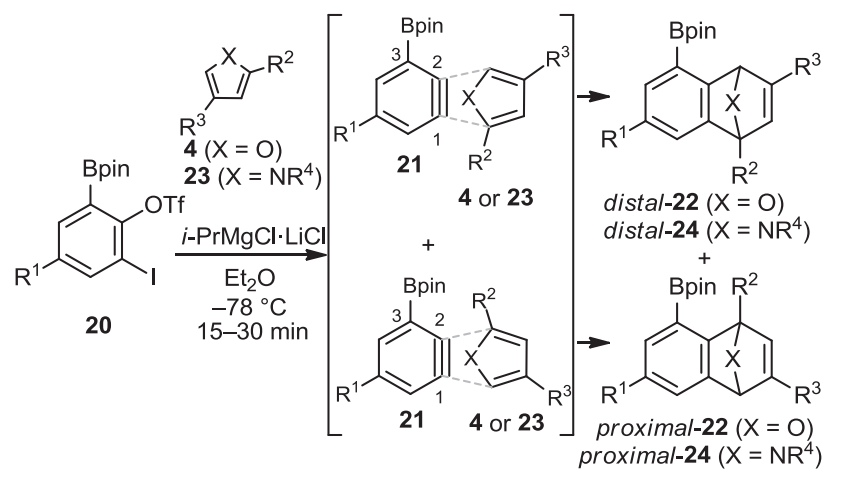

\begin{tabular}{|c|c|c|}
\hline Entry & Major Product & Results \\
\hline \multirow[b]{2}{*}{1} & & $\begin{array}{l}\text { distal-22/proximal-22 }=82: 18 \text { to }>99: 1 \\
40-99 \% \text { total isolated yield }\end{array}$ \\
\hline & sal-2a & $\begin{array}{l}\mathrm{R}^{1}=\mathrm{Me}, \mathrm{Br}, \mathrm{CO}_{2} \mathrm{Me} \\
\mathrm{R}^{2}=\mathrm{Me}, \mathrm{Bu}, \mathrm{SnBu}_{3}, \mathrm{OMe}, \mathrm{CO}_{2} \mathrm{Me}, \text { etc. }\end{array}$ \\
\hline \multirow[b]{2}{*}{2} & & $\begin{array}{l}\text { distal-24/proximal-24 }=87: 13 \text { to }>99: 1 \\
58-72 \% \text { total isolated yield }\end{array}$ \\
\hline & distal-24 $\mathrm{R}^{2}$ & $\begin{array}{l}\mathrm{R}^{1}=\mathrm{Me}, \mathrm{Br}, \mathrm{CO}_{2} \mathrm{Me}, \mathrm{R}^{2}=\mathrm{Et}, \mathrm{Br} \\
\mathrm{R}^{4}=\mathrm{Boc}, \mathrm{Ts}\end{array}$ \\
\hline
\end{tabular}

Interestingly, $\mathbf{2 0} \gamma$ reacted with either 3-methylfuran $\mathbf{4 c}$ or 3-methylpyrrole 23c to produce the corresponding products, proximal-22 $\gamma \mathbf{c}$ and proximal-24 $\gamma \mathbf{c}$, with high regioselectivities, in which the methyl group derived from $\mathbf{4 c}$ and $\mathbf{2 3 c}$ was located close to the boryl group (Scheme 2). This high level of regioselectivity is outstanding compared with the known DA
Scheme 2. DA reactions of 3-borylbenzyne, generated from $\mathbf{2 0} \gamma$, with 3-methylfuran $4 \mathrm{c}$ or 3-methylpyrrole $23 \mathrm{c}$.

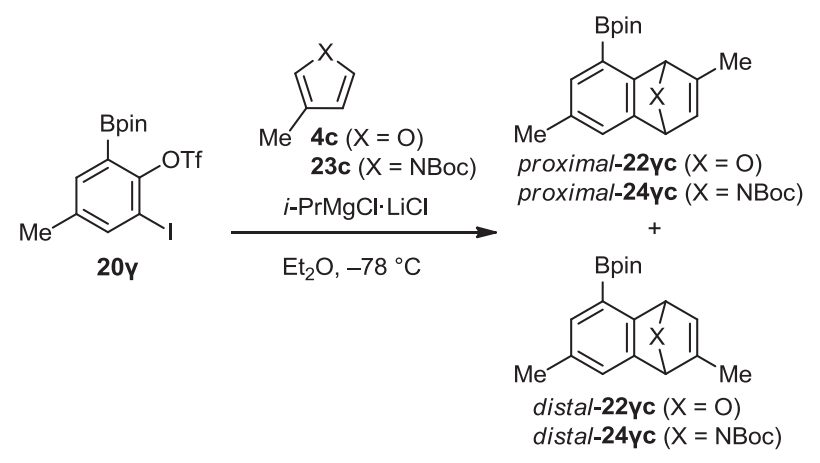

proximal-22yc/distal-22yc $=87: 13(>99 \%$ total isolated yield $)$ proximal-24yc/distal-24yc $=92: 8(95 \%$ total isolated yield $)$

reactions of substituted benzynes and 3-substituted furans. ${ }^{21 a}$

The boryl group of distal-22 $\gamma$ was transformed into amino (Scheme 3, conditions A) and hydroxyl groups (conditions B), while leaving the 1,4-epoxy-1,4-dihydronaphthalene frame intact. Following the acid-catalyzed isomerization of distal$\mathbf{2 2} \gamma$ and distal-24 $\gamma$, Suzuki-Miyaura coupling with aryl iodides gave the biaryl compounds 27 and 28 (Scheme 3). Thus, this series of reactions, namely, the regioselective DA reaction of the borylbenzynes $\mathbf{2 1}$ and the transformation of the boryl group of the adducts, provided a reliable method for the synthesis of multisubstituted benzo-fused compounds.

Scheme 3. Transformations of distal-22 $\gamma$ and distal $-\mathbf{2 4} \gamma$.

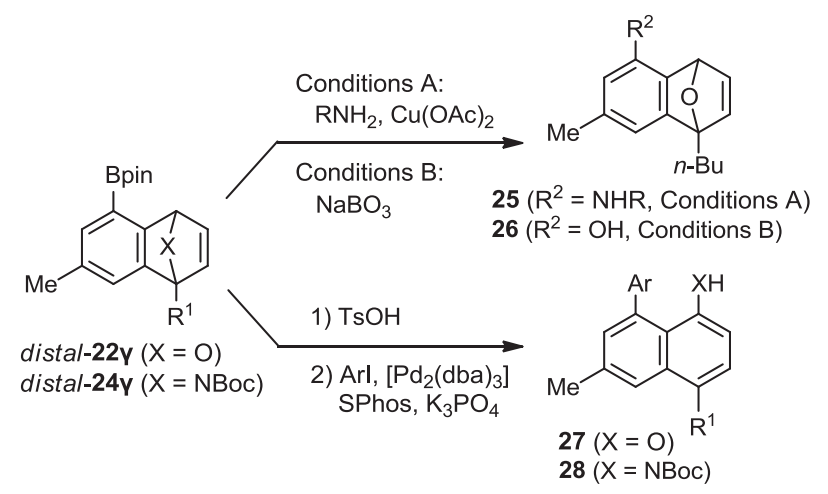

\subsection{Differences between 3-Silylbenzynes and}

3-Borylbenzynes in Diels-Alder Reactions with Furans

As discussed above, in this work, we have demonstrated that silyl and boryl groups effectively control the regioselectivity of the DA reactions of benzynes with furans and with pyrroles. Here, we present a brief comparison of the regioselectivities of the DA reactions of silylbenzynes $7 \mathbf{B} \gamma$ with those of borylbenzynes $\mathbf{2 1} \gamma$ (Scheme 4). The reactions of both $\mathbf{7 B} \gamma$ and $\mathbf{2 1} \gamma$ with 2 -substituted furans (4a and $\mathbf{4 d}$ ) preferentially generated the distal adducts $10 \mathrm{~B} \gamma$ and $22 \gamma$, in which the larger $\mathrm{R}^{2}$ substituent of $\mathbf{4}$ exhibited the higher distal selectivities. On the other hand, we found the following differences between the reactions of $\mathbf{7} \mathbf{B} \gamma$ and those of $\mathbf{2 1} \gamma$. (1) Whereas the steric bulkiness of the substituent of $\mathbf{4}(t-\mathrm{Bu}$ vs. Me) exerted a marked influence on the regioselectivity of $7 \mathbf{B} \gamma$, the steric effect of the substituents of $\mathbf{2 1} \gamma$ was less pronounced (Scheme 4, Eq. 1). (2) The reaction of 3-methylfuran $\mathbf{4} \mathbf{c}$ with $7 \mathbf{B} \gamma$ preferentially furnished the distal adduct $\mathbf{1 0 B} \gamma \mathbf{c}$ (distall 
Scheme 4. Differences between the regiochemistries of the DA reactions of silylbenzynes $7 \mathbf{B} \gamma$ and those of borylbenzynes $\mathbf{2 1} \gamma$.
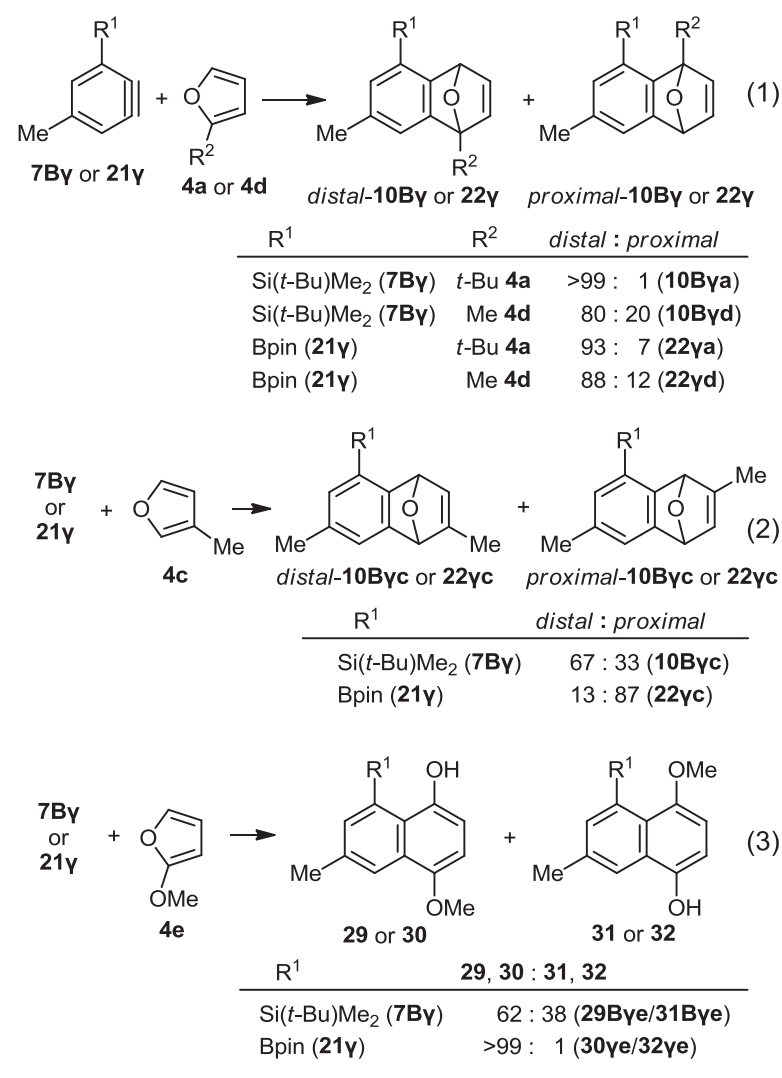

proximal $=67: 33)$, whereas the reaction with $21 \gamma$ selectively produced proximal-22 $\gamma$ c (distallproximal $=13: 87$ ) (Eq. 2). (3) Although the reaction of $\mathbf{7 B} \gamma$ with 2-methoxyfuran $4 \mathbf{e}$ preferentially produced $29 \mathrm{~B} \gamma \mathrm{e}$ with low selectivity $(29 \mathrm{~B} \gamma \mathrm{e} / 31 \mathrm{~B} \gamma \mathrm{e}=$ 62:38) after immediate opening of the 1,4-epoxy ring of the cycloadducts, a similar reaction of $21 \gamma$ with 4 e exclusively provided $\mathbf{3 0} \gamma \mathbf{e}$ (Eq. 3). These results clearly demonstrate that the effect of the silyl group on the regioselectivity of the DA reactions is different from that of the boryl group; the former appears to be caused mainly by steric factors, and the latter, by electrostatic factors.

\section{$2.4[3+2]$ Cycloadditions of 3-Silylbenzynes and 3-Borylbenzynes with 1,3-Dipoles}

One of the most important methods for the synthesis of benzo-fused azole derivatives ${ }^{32}$ is the $[3+2]$ cycloaddition of benzynes with 1,3-dipolar compounds. Since Yamamoto and Jin reported the synthesis of $1 \mathrm{H}$-indazoles by means of the [3 +2 ] cycloaddition of benzynes with diazo compounds in $2007,{ }^{33 a}$ this research area has developed rapidly. ${ }^{33}$ However, the reactions of unsymmetrically substituted benzynes generally generated mixtures of two regioisomers with low selectivities. ${ }^{32 \mathrm{~d}}$ With this background, we addressed the issue of the regiocontrolled synthesis of benzo-fused heteroaromatics using the silyl 7 and borylbenzynes $21 .^{15}$

Because the abovementioned methods for generation of 7 and 21 were not applicable to the [3+2] cycloaddition reactions with various 1,3-dipolar compounds, the initial challenge was the development of milder and more effective conditions using other benzyne precursors. Extensive studies finally revealed

Table 7. Regioselective [3+2] cycloadditions of 3-silylbenzynes 7 or 3-borylbenzynes $\mathbf{2 1}$ with 1,3-dipolar compounds 34-36.

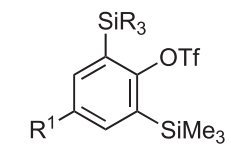<smiles>[R1][X]</smiles>

40

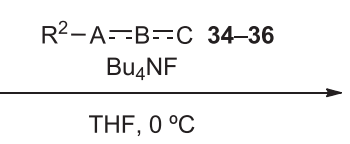

33A: $\mathrm{SiR}_{3}=\mathrm{SiMe}_{3}$ 33B: $\mathrm{SiR}_{3}=\mathrm{Si}(t-\mathrm{Bu}) \mathrm{Me}_{2}$<smiles>[R7]c1cccc(Br)c1</smiles>

7A, 7B<smiles>[R19]C=CC</smiles>

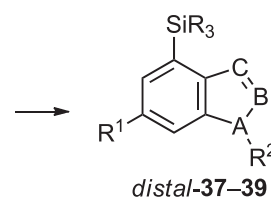<smiles>[R]C1=PCc2cc([R])cc([Se][Ba])c21</smiles>

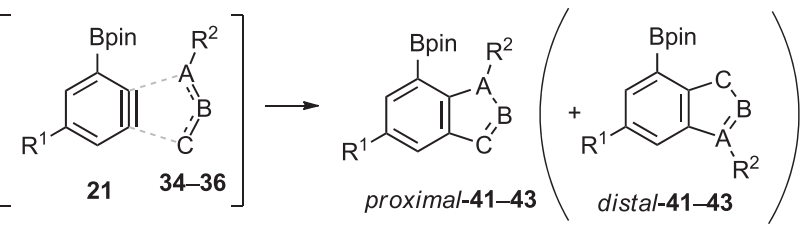

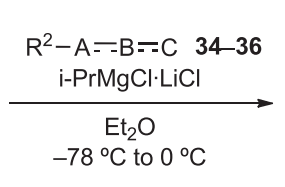

21

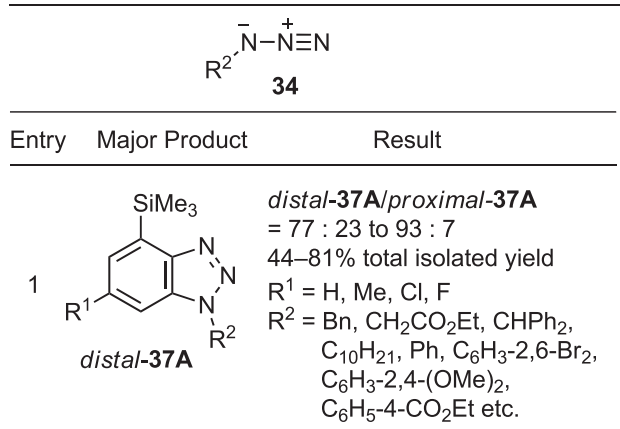

only proximal-41

2<smiles>[R]Oc1cc(Br)cc2nnn([R])c12</smiles>
$\mathrm{R}^{1}=\mathrm{H}, \mathrm{Me}$ $\mathrm{R}^{2}=\mathrm{Bn}, \mathrm{CH}_{2} \mathrm{CO}_{2} \mathrm{Et}, \mathrm{CHPh}_{2}$, $\mathrm{C}_{10} \mathrm{H}_{21}, \mathrm{Ph}, \mathrm{C}_{6} \mathrm{H}_{4}-2-\mathrm{Br}$, $\mathrm{C}_{6} \mathrm{H}_{3}-2,4-(\mathrm{OMe})_{2}$ $\mathrm{C}_{6} \mathrm{H}_{4}-2-\mathrm{Cl}, \mathrm{CH}_{2} \mathrm{C}_{6} \mathrm{H}_{4}-2-\mathrm{CN}$ $\mathrm{CH}_{2} \mathrm{C}_{6} \mathrm{H}_{4}-2-\mathrm{CO}_{2} \mathrm{Me}$ etc.

Entry
$\mathrm{O}^{-}$

Entry Major Product \& Result
39Ay (M = SiMe $\left.e_{3}\right)$
distal-39Ay/proximal-39Ay
$95: 5$
$94 \%$ total isolated yield

$6 \quad 43 y(M=B p i n)$ only distal-43y $64 \%$ isolated yield 
Scheme 5. Syntheses of vorozole 45 and its regioisomer 47 using complementary regioselective [3+2] cycloadditions of silyl- and boryl-benzynes generated from $33 B \varepsilon$ and $40 \varepsilon$.<smiles>COc1cc(C2OCCO2)cc([AsH2])c1OC</smiles>

33B $\varepsilon$

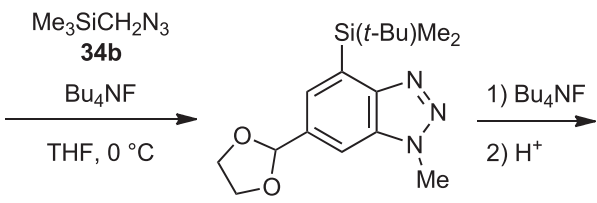

distal-37Brb $(84 \%)$ (distal-37B $\mathbf{\varepsilon b} /$ proximal-37B $\mathbf{\varepsilon b}=94: 6$, $90 \%$ total yield)<smiles>CCOc1cncn1C(CC(C)(C)C)c1ccc(Cl)cc1</smiles>

vorozole $\mathbf{4 5}$<smiles>O=S(=O)(O)c1c(I)cc(C2OCCO2)cc1Cc1ccccc1</smiles>

$40 \varepsilon\left(\mathrm{Ar}=\mathrm{C}_{6} \mathrm{H}_{2}-2,4,5-\mathrm{Cl}_{3}\right)$
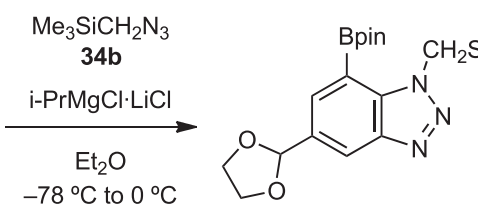

only proximal-41 $\boldsymbol{\varepsilon b}(57 \%)$

that the reaction of 2,6-bis(trimethylsilyl)phenyl triflates 33A with $\mathrm{Bu}_{4} \mathrm{NF}$ and the reaction of 2-boryl-6-iodophenyl 2,4,5trichlorobenzenesulfonate $\mathbf{4 0}$ with $i-\mathrm{PrMgCl} \cdot \mathrm{LiCl}$ were suitable for generating 7 and 21, respectively, in the presence of 1,3-dipolar compounds. Under these conditions, $7 \mathbf{A} \gamma\left(\mathrm{SiR}_{3}\right.$ $=\mathrm{SiMe}_{3}, \mathrm{R}^{1}=\mathrm{Me}$ ), which was generated in situ, immediately reacted with 4-(tert-butyl)phenyl azide $34 \mathbf{a}\left[\mathrm{R}^{2}=\mathrm{C}_{6} \mathrm{H}_{4}-4-(t-\right.$ $\mathrm{Bu})]$ to selectively provide distal-37A $\gamma \mathbf{a}\left[\mathrm{R}^{1}=\mathrm{Me}, \mathrm{R}^{2}=\mathrm{C}_{6} \mathrm{H}_{4}-4-\right.$ $(t-\mathrm{Bu})]$ (distallproximal $=10: 1$, Table 7, entry 1$)$, whereas a similar reaction of $\mathbf{2 1}$ furnished sterically unfavorable proximal$41 \gamma \mathbf{a}\left[\mathrm{R}^{1}=\mathrm{Me}, \mathrm{R}^{2}=\mathrm{C}_{6} \mathrm{H}_{4}-4-(t-\mathrm{Bu})\right]$ exclusively (entry 2$)$.

Subsequent investigation of various [3+2] reactions of 7 and 21 with diverse dipoles 34-36 (Table 7) demonstrated that the reactions of $\mathbf{7}$ with $\mathbf{3 4}$ and $\mathbf{3 5}$ selectively produced distal products (37 and 38) (entries 1 and 3), whereas similar reactions of $\mathbf{2 1}$ generally provided proximal products (41 and 42) (entries 2 and 4). These complementary selectivities provide useful protocols for the preparation of both regioisomers of a range of benzo-fused heterocycles.

Some other features of these reactions are worth noting. (1) Many functional groups such as ester, bromo, chloro, and cyano groups were tolerated under the reaction conditions. (2) The use of 3-(tert-butyldimethylsilyl)benzyne 7B instead of 7A increased the distal selectivity (entry 3). (3) The substituents $\mathrm{R}^{1}(\mathrm{H}, \mathrm{Me}, \mathrm{F}$, and $\mathrm{Cl})$ at the 5 position of the benzynes had little effect on the selectivities of the [3+2] cycloaddition reactions of $\mathbf{7}$ or $\mathbf{2 1}$ with various azides $\mathbf{3 4}$ (entries 1 and 2). (4) The [3+2] cycloaddition of $7 \gamma$ with $\mathrm{TMSCHN}_{2} \mathbf{3 5}^{32 \mathrm{a}}$ selectively provided indazole distal-38 $\gamma$ (entry 3), and similar reactions of $\mathbf{2 1} \gamma$ exclusively furnished proximal-42 $\gamma$ (entry 4). (5) The [3 +2 ] cycloadditions of 7 or $21 \gamma$ with nitrone $36^{34}$ are the only exceptions; both reactions exhibited the same regioselectivity to give distal-39A $\gamma$ and distal-43 $\gamma$ exclusively (entries 5 and 6), whereas all other reactions of 7 and 21d with 1,3-dipoles (34 and 35) exhibited opposite selectivities (entries 1-4).

The developed methods were then applied to the synthesis of vorozole 45, an aromatase inhibitor, ${ }^{35}$ and its regioisomer 47. Starting from suitably functionalized precursors $(33 B \varepsilon$ and

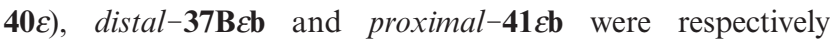
obtained, each with high regioselectivity. These adducts were easily converted into 45 and $\mathbf{4 7}$, respectively (Scheme 5). Therefore, the complementary synthesis of diverse benzofused heterocycles such as distal-37 and proximal-41 should

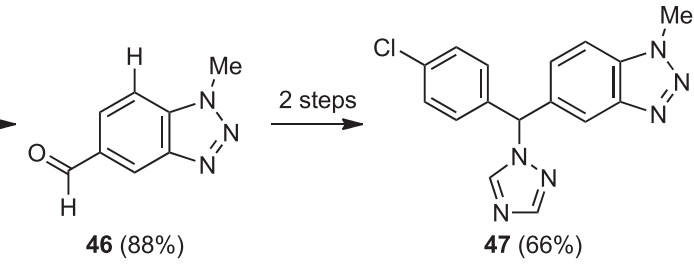

serve as useful synthetic tools for drug discovery.

\subsection{Nucleophilic Addition to 3-Silylbenzynes}

The silyl group also produced the regioselective nucleophilic addition of primary amines 48 to 7 A. ${ }^{13}$ Despite possible steric repulsion between the approaching $\mathbf{4 8}$ and the bulky trimethylsilyl group, the reaction occurred preferentially at the 2 position of 7A to furnish ortho-49A (Scheme 6). This unique ortho-selectivity was widely demonstrated by the reactions of various 7A with $\mathbf{4 8}$, and a range of functional groups such as fluoro, chloro, silyloxy, furyl, hydroxyl, amino, and carbamoyl groups, were tolerated.

Scheme 6. ortho-Selective nucleophilic additions of amines 48 to silylbenzynes $\mathbf{7 A}$.

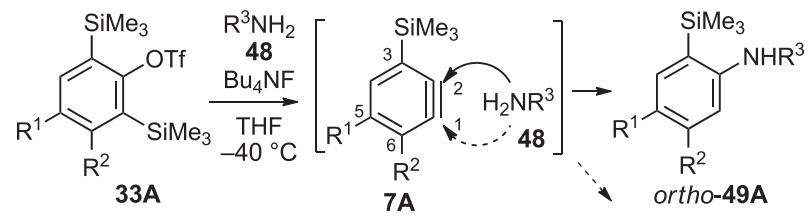

$\mathrm{R}^{1}=\mathrm{H}, \mathrm{Me}, \mathrm{F}, \mathrm{Cl}, \mathrm{Ph}, \mathrm{CH}_{2} \mathrm{OSi}(t-\mathrm{Bu}) \mathrm{Me}_{2}, \mathrm{OMe}$ $\mathrm{R}^{2}=\mathrm{H}, \mathrm{Me}$

$\mathrm{R}^{3}=\mathrm{H}, \mathrm{Me}$, furfuryl, $\left(\mathrm{CH}_{2}\right)_{5} \mathrm{OH},\left(\mathrm{CH}_{2}\right)_{2} \mathrm{NH}_{2}$ $\mathrm{CH}_{2} \mathrm{Ph}$, cyclohexyl, allyl, $\mathrm{NHBoc}, \mathrm{NHCbz}$ etc ortho-49A $/$ meta-49A $=82: 18$ to $>99: 1$ (57-94\% total isolated yield)

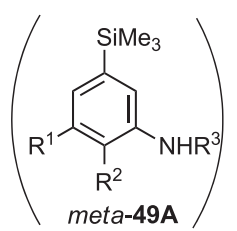

\section{Discussion ${ }^{12 \mathrm{~b}, 14 \mathrm{~b}, 15}$}

The origin of the regioselectivities in the DA reactions, [3 +2 ] cycloaddition reactions, and nucleophilic addition reactions of silyl- and boryl-benzynes (7 and 21) were theoretically evaluated based on DFT calculations at the B3LYP/6$31 \mathrm{G}(\mathrm{d})$ level using the Gaussian09 program package. ${ }^{36}$

Initially, the electron densities at $\mathrm{C} 1$ and $\mathrm{C} 2$ of some 3substituted benzynes (7A $\alpha, 7 \mathrm{~B} \alpha, 7 \mathrm{~B} \gamma, 7 \mathrm{D} \alpha, 21 \alpha, 21 \gamma, \mathbf{5 0}, \mathbf{5 1}$, and $6 \alpha$ ) were calculated using the natural bond orbital (NBO) method $^{37,38}$ in order to evaluate the electrostatic effect of the substituents. It was found that the electron densities at $\mathrm{C} 1$ of $7 \mathrm{~s}$ and 21s were higher than those at $\mathrm{C} 2$, whereas those of $\mathbf{5 0}$ and 51 exhibited the opposite trend. In the case of $6 \alpha$, these two carbons had almost the same electron density. On the other hand, the substituents $(\mathrm{H}$ and $\mathrm{Me})$ at the 5 position of benzynes had little influence on the electron densities (Figure 2). 


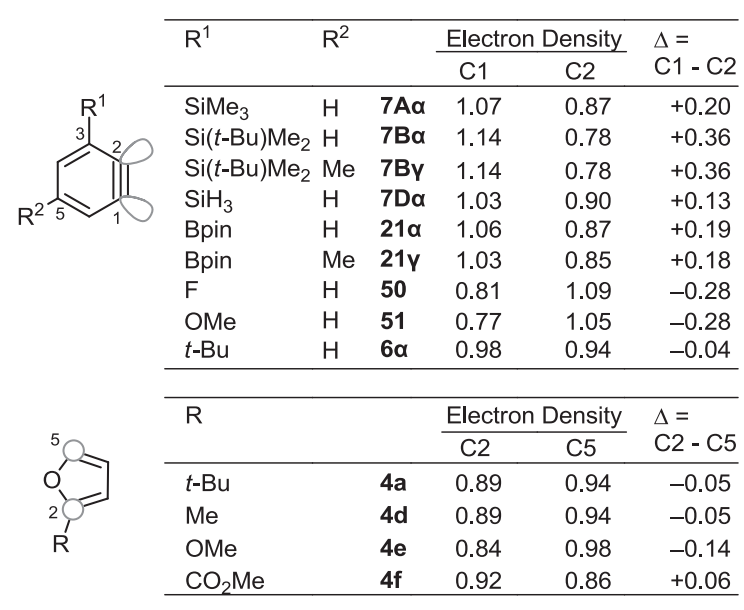

Figure 2. Electron densities at $\mathrm{C} 1$ and $\mathrm{C} 2$ of various benzynes $(7 \mathrm{~A} \alpha$, 7B $\alpha, 7 \mathrm{~B} \gamma, 7 \mathrm{D} \alpha, \mathbf{2 1} \alpha, \mathbf{2 1} \gamma, \mathbf{5 0}, \mathbf{5 1}$, and $\mathbf{6} \alpha)$ and those at $\mathrm{C} 2$ and $\mathrm{C} 5$ of furans $(\mathbf{4 a}, \mathbf{4 d}-\mathbf{4 f})$ calculated by NBO method.

In a similar manner, it was found that alkyl and alkoxy groups at the 2 position of furans $\mathbf{4 a}, \mathbf{4 d}, \mathbf{4 e}$, and $\mathbf{4 f}$ enhanced the electron density at $\mathrm{C} 5$ compared to $\mathrm{C} 2$, and the presence of a methoxycarbonyl group made $\mathrm{C} 5$ more electron-deficient.

The electrostatic interactions between benzynes $(7 \mathbf{B} \gamma$ and $\mathbf{2 1} \gamma$ ) and furans (4d and $\mathbf{4 e}$ ) roughly account for the experimentally favorable orientation of their DA reactions (Figure 3). However, this explanation is inadequate to describe a similar interaction between $\mathbf{2 1} \gamma$ and $\mathbf{4} \mathbf{f}$ for the preferential formation of distal-22 $\gamma \mathbf{f}$. The DA reaction of $\mathbf{2 1} \gamma$ and $\mathbf{4 f}$ was also evaluated based on theoretical analysis using the frontier orbital theory; ${ }^{39}$ however, the HOMO-LUMO interaction of these reactants did not provide an adequate platform for understanding its anomalous orientation. These results clearly indicated that the electrostatic and/or orbital interaction of the reactants were not sufficient for a global and quantitative explanation of the experimental regioselectivity.

In order to rationalize the origin of the regioselectivities, reaction pathway analysis of the DA reactions, including the transition states (TSs), ${ }^{40}$ was subsequently executed. The TS could be determined for nine reactions of silylbenzynes $7 \mathbf{B}$ with 4. For example, distal-TS10B $\gamma \mathbf{d}$ leading to distal-10B $\gamma \mathbf{d}$ is $0.82 \mathrm{kcal} / \mathrm{mol}$ lower than proximal-TS10B $\gamma \mathbf{d}$ leading to proximal-10B $\gamma \mathbf{d}$, which theoretically indicates an 80:20 distal selectivity (Figure 4A) and is in excellent agreement with the experimental result (distal-10B $\gamma \mathbf{d} /$ proximal $-\mathbf{1 0 B} \gamma \mathbf{d}=80: 20$, Scheme 4, Eq. 1). We could also identify the TSs for fourteen

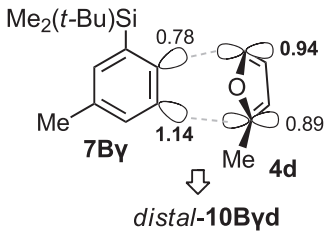

distal-10Byd/proximal-10Byd $=80: 20$

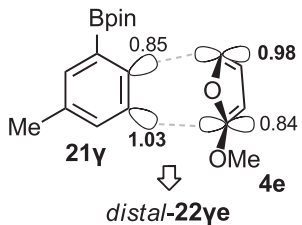

distal-22ye/proximal-22ye $=>99: 1$

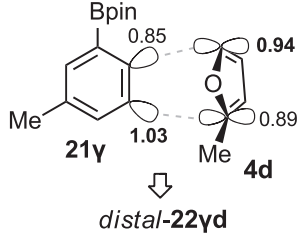

distal-22yd/proximal-22yd $=88 \cdot 12$

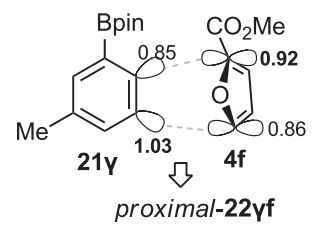

distal-22yf/proximal-22yf $=93: 7$

Figure 3. Electrostatic interaction between benzynes (7B $\gamma$ and $21 \gamma)$ and furans $\mathbf{4 d}-\mathbf{4 f}$ by natural bond orbital (NBO) analysis. Numerals beside orbital lobes indicate electron density of the NBO. The distal-to-proximal ratio of each reaction indicates the experimental result.

reactions of borylbenzynes $\mathbf{2 1}$ with either $\mathbf{4}$ or pyrroles $\mathbf{2 3}$. All theoretical distal-to-proximal ratios of the adducts (10 and 22) based on the potential energy differences between distalTSs and proximal-TSs were in good agreement with the experimentally determined ratios. Thus, the reliability of the theoretically determined TSs was deemed acceptable. These results also suggested that the regioselectivities of the DA reactions were critically controlled by the TSs.

In order to further evaluate the origin of the regioselectivities, the structures of these TSs were extensively characterized. They were also compared with the TSs of the DA reactions of $\mathbf{7}$ or $\mathbf{2 1}$ with unsubstituted furan $\mathbf{4 g}$ as standard references. The following findings are noteworthy:

(1) The results of characterization of the TSs (TS10D $\alpha$, TS10A $\alpha \mathrm{g}, \operatorname{TS10B} \alpha \mathrm{g}$, and TS22 $\alpha \mathrm{g}$ ) of the DA reactions of some silyl- (7D $\alpha, 7 \mathrm{~A} \alpha$, and $7 \mathbf{B} \alpha)$ and boryl-benzynes $21 \alpha$ with unsubstituted furan $\mathbf{4 g}$, including vibration, indicated that all reactions proceeded via the non-synchronous concerted mechanism (Figure 5). Although the charge distribution of silylbenzyne 7A $\alpha$ and that of borylbenzyne $21 \alpha$ are quite similar (Figure 2), the structures of TS10A $\alpha$ g and TS22 $\alpha \mathbf{g}$ are very different. In the case of TS10A $\alpha$ g, the distance between $\mathrm{C} 2$ of $7 \mathrm{~A} \alpha$ and $\mathbf{4 g}$ is longer than that between $\mathrm{C} 1$ and $\mathbf{4 g}$, whereas in $\mathbf{T S 2 2} \alpha \mathbf{g}$, the distance between $\mathrm{C} 2$ of $\mathbf{2 1} \alpha$ and $\mathbf{4 g}$ is

(A)

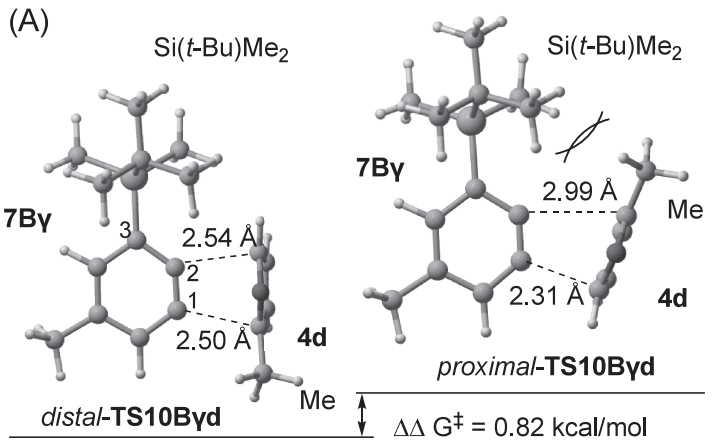

(B)

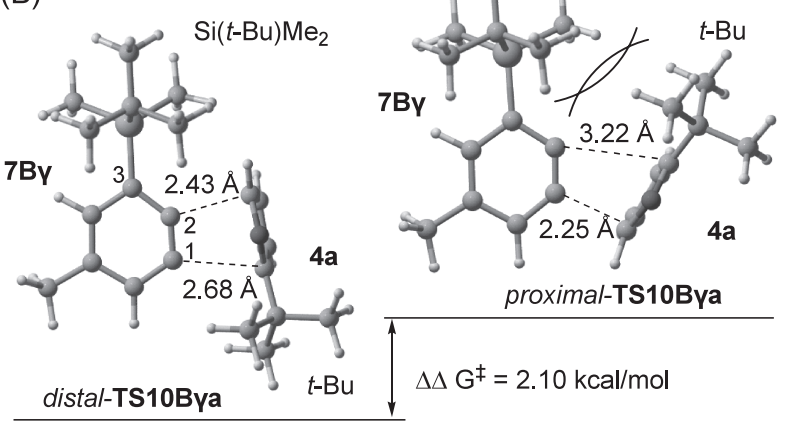

Figure 4. Two most possible transition states of the DA reaction between silylbenzyne 7B $\gamma$ and $2-$ substituted furans [2-methylfuran 4d (Fig. 4A) and 2-tert-butylfuran 4a (Fig. 4B)]. 

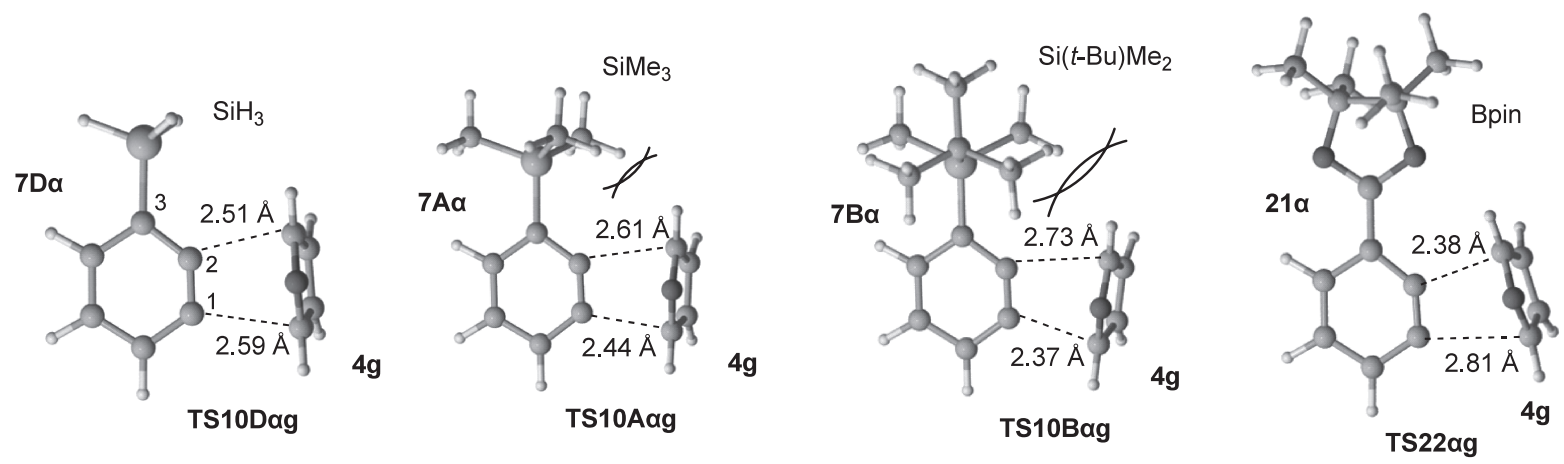

Figure 5. Transition states (TS10D $\alpha \mathrm{g}, \operatorname{TS10A} \alpha \mathrm{g}, \operatorname{TS10B} \alpha \mathrm{g}$ and TS22 $\alpha \mathrm{g}$ ) of DA reactions between silylbenzyne $7 \alpha$ or borylbenzyne $21 \alpha$ and unsubstituted furan $\mathbf{4 g}$.
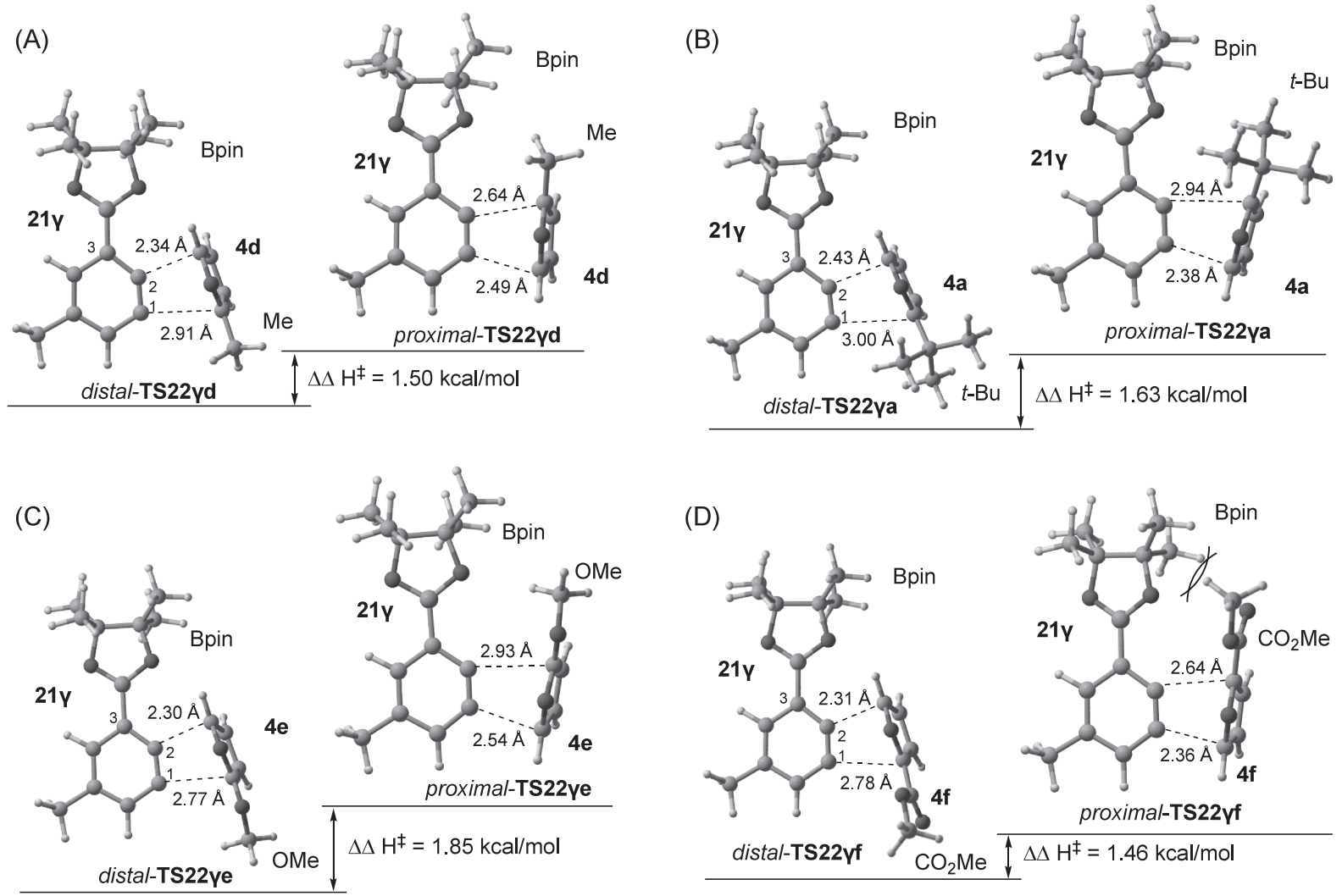

Figure 6. Two most possible transition states of the DA reaction between borylbenzyne $21 \gamma$ and $2-$ substituted furans [2-methylfuran 4d (Fig. 6A), 2-tert-butylfuran 4a (Fig. 6B), 2-methoxyfuran 4e (Fig. 6C), and 2-(methoxycarbonyl)furan 4f (Fig. 6D)].

much shorter than that between $\mathrm{Cl}$ and $\mathbf{4 g}$ (Figure 5). The structures of TS10A $\alpha$ g and $\mathbf{T S 1 0 B} \alpha \mathbf{g}$ show a large steric repulsion between the silyl groups and the hydrogen of $\mathbf{4 g}$, while the structure of $\mathbf{T S 2 2} \alpha \mathbf{g}$ clearly reflects the inherent electron density of $21 \alpha$.

(2) In proximal-TS10B $\gamma \mathbf{d}$ and -TS10B $\gamma \mathbf{a}$ (Figures 4A and $4 \mathrm{~B})$, the steric repulsion between the silyl group and the substituents at the 2 position of furans (4d or $\mathbf{4 a}$ ) is even greater, thus enlarging the potential energy difference between the distal and proximal TSs. In particular, in proximal-TS10B $\gamma \mathbf{a}$ bearing the bulkier $t$-butyl group, the potential energy difference is much larger. On the other hand, in the case of borylbenzynes $21 \gamma$ (Figures 6A and 6B), the structural difference between proximal-TS22 $\gamma \mathbf{d}$ and proximal-TS22 $\gamma$ a is relatively small, and the potential energy differences between the distal and proximal TSs are also small. These contrasting results clearly indicate that the regioselectivities of the DA reactions of the silylbenzynes 7 are mainly determined by the steric repulsion between $\mathbf{7}$ and $\mathbf{4}$ in addition to their inherent electrostatic interactions, whereas those of borylbenzynes $\mathbf{2 1}$ are mainly determined by their electrostatic interactions with 4 .

(3) The DA reaction of borylbenzyne $\mathbf{2 1} \gamma$ with 2-methoxyfuran $\mathbf{4 e}$ and that with 2-(methoxycarbonyl)furan $\mathbf{4 f}$ were both distal selective (Table 6, entry 1), among which the latter cannot be accounted for by the electrostatic interaction between $\mathbf{2 1} \gamma$ and $\mathbf{4 f}$ (Figure 3). In proximal-TS22 $\gamma \mathbf{f}$ (Figure 6D), which is electrostatically more favorable than distal-TS22 $\gamma \mathbf{f}$, the length $(2.64 \AA)$ of the forming bond at the 2 position of $21 \gamma$ is much shorter than those in proximal-TS22 $\gamma \mathbf{a}(2.94 \AA)$ and proximal-TS22 $\gamma$ e $(2.93 \AA$ ) (Figures 6B and 6C). Therefore, proximal-TS22 $\gamma \mathbf{f}$ is susceptible to the large steric repulsion between the boryl and the methoxycarbonyl groups and is 
(A)

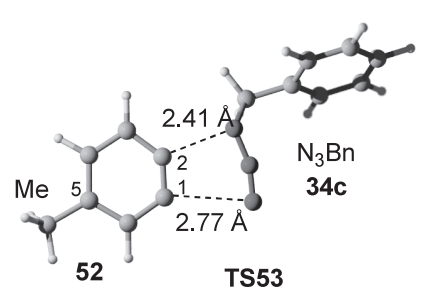

(B)

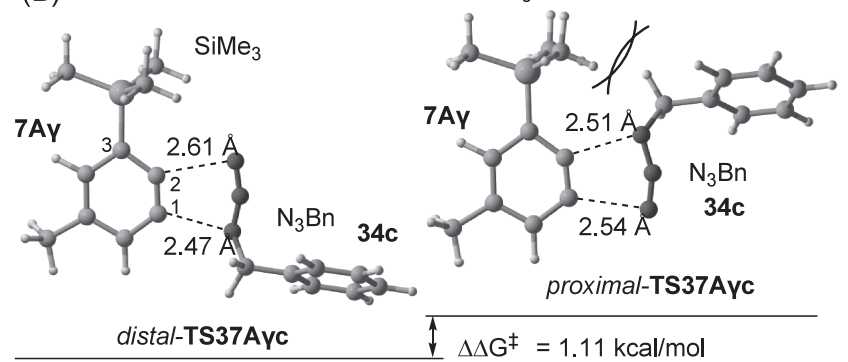

(C)

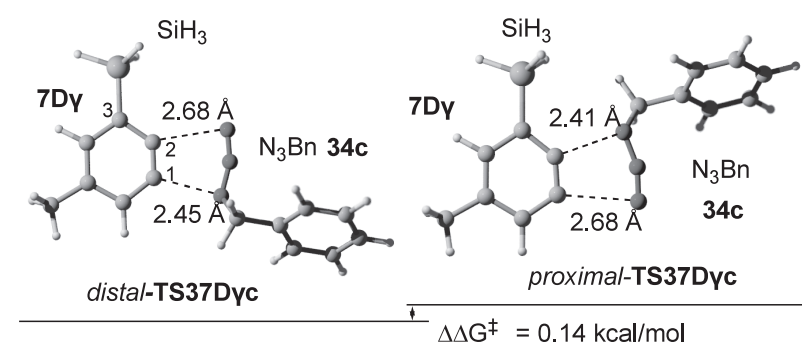

(D)

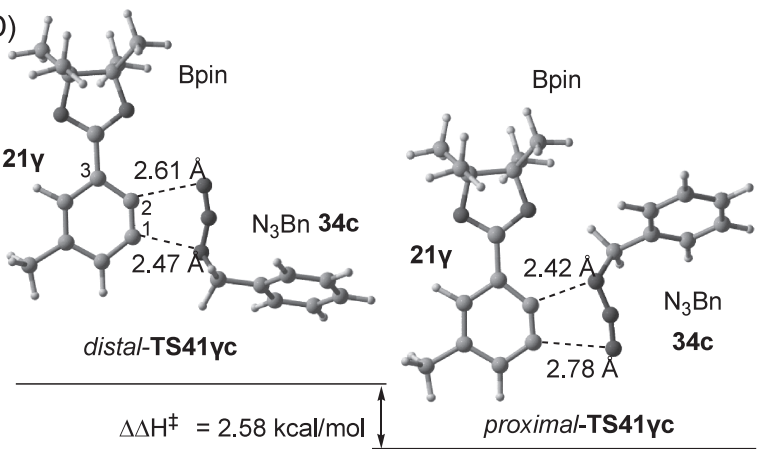

Figure 7. Transition state of the [3+2] cycloaddition reaction between benzyl azide $\mathbf{3 4 c}$ and benzyne $\mathbf{5 2}$ (Fig. 7A). Two most possible transition states of the [3+2] cycloaddition reactions between benzyl azide 34c and benzynes [7A $\gamma$ (Fig. 7B), 7D $\gamma$ (Fig. 7C), and $21 \gamma$ (Fig. 7D)].

quite unstable. Consequently, the alternative distal-TS22 $\gamma \mathbf{f}$, which is electrostatically less favorable, becomes relatively more stable.

The TSs (TS53, TS37A $\gamma \mathbf{c}$, TS37D $\gamma \mathbf{c}$, and TS41 $\gamma \mathbf{c})$ of the $[3+2]$ cycloaddition reactions between benzynes $(\mathbf{5 2}, \mathbf{7} \mathbf{A} \gamma, \mathbf{7 D} \gamma$, and $21 \gamma$ ) and benzyl azide 34c (Figure 7) were also analyzed. TS53 shows the nature of the electrostatic interaction between 5-methylbenzyne $\mathbf{5 2}$ and $\mathbf{3 4 c}$, in which the bond distance (2.41 $\AA$ ) between the internal nitrogen of $\mathbf{3 4} \mathbf{c}$ and the carbon of the benzyne is shorter than that $(2.77 \AA)$ between the terminal nitrogen and the carbon of the benzyne (Figure 7A). Proximal-TS37A $\gamma \mathbf{c}$, in which the distance $(2.51 \AA)$ between the internal nitrogen and the $\mathrm{C} 2$ of the benzyne is greater than the corresponding distance in TS53, demonstrates that there is a very large steric repulsion between the trimethylsilyl group and the benzyl group (Figure 7B). This makes the electrostatically favorable proximal-TS37A $\gamma \mathbf{c}$ less stable than distal-TS37A $\gamma \mathbf{c}$, thereby resulting in the preferential production of distal$37 \mathbf{A} \gamma \mathbf{c}$. The potential energy difference $(1.11 \mathrm{kcal} / \mathrm{mol})$ corresponds to $87: 13$ distal selectivity, which is reasonable in the context of our experimental result (distal-37A $\gamma \mathbf{c} /$ proximal37A $\gamma \mathbf{c}=77: 23$ ). Analysis of two TSs (distal-TS37D $\gamma \mathbf{c}$ and proximal-TS37D $\gamma \mathbf{c}$ ) derived from a virtual benzyne 7D $\gamma$ possessing a $\mathrm{SiH}_{3}$ group demonstrated that the potential energy difference between these two TSs was very small $(0.14 \mathrm{kcal} /$ mol) (Figure 7C). These results suggest that the steric bulkiness of the silyl groups has a significant adverse influence on the electrostatically favorable proximal TSs, and that steric repulsion is the governing factor for the production of distal adducts in the [3+2] cycloaddition reaction of 7 .

In the [3+2] cycloaddition reaction of $\mathbf{2 1} \gamma$ with $\mathbf{3 4 c}$, proximal-TS41 $\gamma \mathbf{c}$ is $2.58 \mathrm{kcal} / \mathrm{mol}$ lower than distal-TS41 $\gamma \mathbf{c}$ (Figure 7D), which theoretically corresponds to $1:>99$ proximal selectivity and is in good agreement with our experimental result (distal-41 $\gamma \mathbf{c} /$ proximal $\mathbf{- 4 1} \gamma \mathbf{c}=1:>99$ ). The structure of proximal-TS41 $\gamma \mathbf{c}$, where the electrostatic combination of the reacting atoms is well matched, is very close to that of TS53 (Figures 7A and 7D). This implies that the boryl group exerts little adverse steric effect on proximal-TS41 $\gamma \mathbf{c}$ and governs the formation of proximal $\mathbf{- 4 1} \gamma \mathbf{c}$.

The DFT analyses of the ground and transition state structures of the benzyne reactions proved to be quite effective for quantitative interpretation of the intriguing and characteristic properties of the silyl and boryl groups. The electrostatic attractive interactions of the two reactants and the steric repulsion between the approaching substituents were found to be the most significant factors dominating the regioselectivities. Thus, the DA reactions of both silyl and borylbenzynes were controlled by the synergy of the electrostatic and steric effects. On the other hand, in the $[3+2]$ cycloaddition reactions, the silylbenzynes were determined to be more susceptible to steric effects, whereas the reactions of the borylbenzynes were more electrostatically dominated.

\section{Conclusion}

A novel method for the regiocontrol of benzyne reactions was developed using silyl and boryl substituents. Similar regioselectivities were observed in the DA reactions of both silyl and borylbenzynes. On the other hand, complementary regioselectivities were exhibited by these two species in the $[3+2]$ cycloaddition reactions. Given that the silyl and boryl groups of the products are convertible into carbon-, oxygen-, and nitrogen-substituents as well as hydrogen, the developed protocol serves as a useful preparation strategy for developing multisubstituted benzo-fused compounds. The regioselectivities of these reactions were quantitatively interpreted on the basis of analysis of the transition state structures obtained from DFT calculations, revealing that steric effects governed 
the reactions of the silyl groups, whereas the reactivity of the boryl group was exclusively governed by electrostatic effects.

Thus, the current account provides insight into certain longstanding problems related to the regioselectivity of benzyne reactions. However, the selectivities and reactivities of other benzynes remain uninvestigated. Further studies towards these goals are currently underway in our laboratory.

\section{Acknowledgement}

The authors express their sincere gratitude to co-workers and all present and past laboratory members. Further, the authors thank Professor Yasuyuki Kita for fruitful suggestions concerning this work, and Professor Satoshi Fujii and Professor Yoshinobu Ishikawa for their important computational discussions. This work was supported by KAKENHI and a Grant-in-Aid for the Global COE Program from MEXT. Uehara Memorial Foundation and Hoansha Foundation are acknowledged for financial support. Further, IT is grateful for receiving the Daicel Chemical Industry Award in Synthetic Organic Chemistry (Japan). Professor Philip Hawke is acknowledged for the assistance in preparing this manuscript.

\section{References}

1) For recent reviews: (a) Wenk, H. H.; Winkler, M.; Sander, W. Angew. Chem. Int. Ed. 2003, 42, 502. (b) Worlikar, S. A.; Larock, R. C. Curr. Org. Chem. 2011, 15, 3214. (c) Bhunia, A.; Yetra, S. R.; Biju, A. T. Chem. Soc. Rev. 2012, 41, 3140. (d) Tadross, P. M.; Stoltz, B. M. Chem. Rev. 2012, 112, 3550.

2) Bachmann, W. E.; Clarke, H. T. J. Am. Chem. Soc. 1927, 49, 2089

3) (a) Wittig, G. Naturwissenschaften 1942, 30, 3209. (b) Roberts, J. D.; Simmons, Jr., H. E.; Carlsmith, L. A.; Vaughan, C. W. J. Am. Chem. Soc. 1953, 75, 3290.

4) (a) Chapman, O. L.; Mattes, K.; McIntosh, C. L.; Pacansky, J.; Calder, G. V.; Orr, G. J. Am. Chem. Soc. 1973, 95, 6134. (b) Chapman, O. L.; Chang, C. C.; Kolc, J.; Rosenquist, N. R.; Tomioka, H. J. Am. Chem. Soc. 1975, 97, 6586 .

5) (a) Himeshima, Y.; Sonoda, T.; Kobayashi, H. Chem. Lett. 1983, 1211. (b) Peña, D.; Cobas, A.; Pérez, D.; Guitián, E. Synthesis 2002, 1454. Our recent contribution to benzyne generation, see: (c) Ikawa, T.; Nishiyama, T.; Nosaki, T.; Takagi, A.; Akai, S. Org. Lett. 2011, 13, 1730.

6) A recent review of synthetic methods for naphthalenes: de Koning, C. B.; Rousseau, A. L.; van Otterlo, W. A. L. Tetrahedron 2003, 59, 7.

7) (a) Anderson, J. E.; Franck, R. W.; Mandella, W. L. J. Am. Chem. Soc. 1972, 94, 4608. (b) Newman, M. S.; Kannan, R. J. Org. Chem. 1976, 41, 3356. (c) Shankaran, K.; Snieckus, V. Tetrahedron Lett. 1984, 25, 2827. (d) Gribble, G. W.; Keavy, D. J.; Branz, S. E.; Kelly, W. J.; Pals, M. A. Tetrahedron Lett. 1988, 29, 6227. (e) Matsumoto, T.; Hosoya, T.; Katsuki, M.; Suzuki, K. Tetrahedron Lett. 1991, 32, 6735. (f) Giles, R. G. F.; Hughes, A. B.; Sargent, M. V. J. Chem. Soc., Perkin Trans. 1 1991, 1571. (g) Nishiyama, T.; Okada, M.; Miyazawa, M. Reports of Kyushu School of Engineering, Kinki University 2000, 28, 37.

8) Selected silyl-directed reactions: (a) Boebel, T. A.; Hartwig, J. F. J. Am. Chem. Soc. 2008, 130, 7534. (b) Robbins, D. W.; Boebel, T. A.; Hartwig, J. F. J. Am. Chem. Soc. 2010, 132, 4068.

9) Selected boryl-directed reactions: (a) Auvinet, A.-L.; Harrity, J. P. A. Angew. Chem. Int. Ed. 2011, 50, 2769. (b) Kirkham, J. D.; Butlin, R. J.; Harrity, J. P. A. Angew. Chem. Int. Ed. 2012, 51, 6402.

10) Matsumoto, T.; Sohma, T.; Hatazaki, S.; Suzuki, K. Synlett 1993, 843.

11) The DA reaction between 3-fluoro-6-(trimethylsilyl)benzyne and 2(trimethylsilyl)furan was reported to exclusively generate 1,5bis(trimethylsilyl)-1,4-epoxy-8-fluoro-1,4-dihydronaphthalene. However, the DA reaction of the simple 3-(trimethylsilyl)benzyne was not examined, see: Masson, E.; Schlosser, M. Eur. J. Org. Chem. 2005, 4401 .

12) Regioselective DA of silylbenzynes, see: (a) Akai, S.; Ikawa, T.; Takayanagi, S.; Morikawa, Y.; Mohri, S.; Tsubakiyama, M.; Egi, M.; Wada, Y.; Kita, Y. Angew. Chem. Int. Ed. 2008, 47, 7673. (b) Ikawa, T.; Takayanagi, S.; Morikawa, Y.; Mohri, S.; Takagi, A.; Aoyama, Y.; Tsubakiyama, M.; Itoh, Y.; Tokiwa, H.; Ishikawa, Y.; Kita, Y.; Akai, S. submitted for publication.
13) Regioselective nucleophilic additions of silylbenzynes, see: (a) Ikawa, T.; Nishiyama, T.; Shigeta, T.; Mohri, S.; Morita, S.; Takayanagi, S.; Terauchi, Y.; Morikawa, Y.; Takagi, A.; Ishikawa, Y.; Fujii, S.; Kita, Y.; Akai, S. Angew. Chem. Int. Ed. 2011, 50, 5674. (b) Bronner, S. M.; Mackey, J. L.; Houk, K. N.; Garg, N. K. J. Am. Chem. Soc. 2012, ASAP.

14) Regioselective DA of borylbenzynes, see: (a) Ikawa, T.; Takagi, A.; Kurita, Y.; Saito, K.; Azechi, K.; Egi, M.; Kakiguchi, K.; Kita, Y.; Akai, S. Angew. Chem. Int. Ed. 2010, 49, 5563. (b) Takagi, A.; Ikawa, T.; Kurita, Y.; Saito, K.; Azechi, K.; Egi, M.; Itoh, Y.; Tokiwa, H.; Kita, Y.; Akai, S. submitted for publication.

15) Regioselective [3+2] cycloadditions of silyl- and borylbenzynes, see: Ikawa, T.; Takagi, A.; Goto, M.; Aoyama, Y.; Ishikawa, Y.; Itoh, Y.; Fujii, S.; Tokiwa, H.; Akai, S. submitted for publication.

16) (a) Baudoin, O.; GuHritte, F. Stud. Nat. Prod. Chem. 2003, 29, 355 (b) Brunel, J. M. Chem. Rev. 2005, 105, 857. (c) Berthod, M.; Mignani, G.; Woodward, G.; Lemaire, M. Chem. Rev. 2005, 105, 1801. (d) Mei, X.; Wolf, C. J. Am. Chem. Soc. 2006, 128, 13326.

17) Some other examples of the DA reactions of benzynes having a bulky group: (a) Franck, R. W.; Leser, E. G. J. Org. Chem. 1970, 35, 3932. (b) Anderson, J. E.; Franck, R. W.; Mandella, W. L. J. Am. Chem. Soc. 1972, 94, 4608. (c) Handal, J.; White, J. G.; Franck, R. W.; Yuh, Y. H.; Allinger, N. L. J. Am. Chem. Soc., 1977, 99, 3345. (d) Anderson, J. E.; Franck, R. W. J. Chem. Soc., Perkin Trans. 2, 1984, 1581. (e) Aikawa, H.; Takahira Y.; Yamaguchi, M. Chem. Commun., 2011, 47, 1479.

18) Metal-Catalyzed Cross-Coupling Reactions, 2nd ed.; de Meijere, A.; Diederich, F., Eds.; Willey-VCH: Weinheim, 2004.

19) (a) Hiyama, T. J. Organomet. Chem. 2002, 653, 58. (b) Denmark, S. E.; Ober, M. H. Aldrichimica Acta 2003, 36, 75.

20) (a) Taguchi, H.; Ghoroku, K.; Tadaki, M.; Tsubouchi, A.; Takeda, T. J. Org. Chem. 2002, 67, 8450. (b) Nakao, Y.; Imanaka, H.; Sahoo, A. K.; Yada, A.; Hiyama, T. J. Am. Chem. Soc. 2005, 127, 6952.

21) For some examples of acid-catalyzed opening of 1,4-epoxy-1,4dihydronaphthalenes, see: (a) Batt, D. G.; Jones, D. G.; La Greca, S. J. Org. Chem. 1991, 56, 6704. (b) Schlosser, M.; Castagnetti, E. Eur. J. Org. Chem. 2001, 3991. (c) Kaelin, D. E.; Sparks, S. M.; Plake, H. R.; Martin, S. F. J. Am. Chem. Soc. 2003, 125, 12994. (d) Nrgel, S. S. Azap, C.; Reißig, H.-U. Eur. J. Org. Chem. 2006, 4405.

22) For examples of intermolecular fluoride-free Hiyama reactions, see: Alacid, E.; Nájera, C. Adv. Synth. Catal. 2006, 348, 2085.

23) After the publication of our work, the following paper was published: Tsubouchi, A.; Matsuda, H.; Kira, T.; Takeda, T. Chem. Lett. 2009, 38,1180 .

24) Synthesis of 1,8-dihydroxynaphthalene: Lurie, A. P.; Brown, G. H.; Thirtle, J. R.; Weissberger, A. J. Am. Chem. Soc. 1961, 83, 5015.

25) (a) Tamao, K.; Kakui, T.; Akita, M.; Iwahara, T.; Kanatani, R.; Yoshida, J.; Kumada, M. Tetrahedron 1983, 39, 983. (b) Fleming, I.; Henning, R.; Plaut, H. J. Chem. Soc., Chem. Commun. 1984, 29.

26) (a) Miyaura, N.; Suzuki, A. Chem. Rev. 1995, 95, 2457. (b) Monnier, F.; Taillefer, M. Angew. Chem. Int. Ed. 2009, 48, 6954.

27) For selected examples, see: (a) Shinkai, S.; Takeuchi, M. Biosens. Bioelectron. 2004, 20, 1250. (b) Elfeky, S. A.; Flower, S. E.; Masumoto, N.; Dhooge, F.; Labarthe, L.; Chen, W.; Len, C.; James, T. D.; Fossey, J. S. Chem. Asian J. 2010, 5, 581.

28) For recent examples, see: (a) Baker, S. J.; Zhang, Y.-K.; Akama, T.; Lau, A.; Zhou, H.; Hernandez, V.; Mao, W.; Alley, M. R. K.; Sanders, V.; Plattner, J. J. J. Med. Chem. 2006, 49, 4447. (b) Dorsey, B. D.; Iqbal, M.; Chatterjee, S.; Menta, E.; Bernardini, R.; Bernareggi, A.; Cassar, P. G.; D’Arasmo, G.; Ferretti, E.; De Munari, S.; Oliva, A.; Pezzoni, G.; Allievi, C.; Strepponi, I.; Ruggeri, B.; Ator, M. A.; Williams, M.; Mallamo, J. P. J. Med. Chem. 2008, 51, 1068.

29) (a) Lin, W.; Chen, L.; Knochel, P. Tetrahedron 2007, 63, 2787. (b) Sapountzis, I.; Lin, W.; Fischer, M.; Knochel, P. Angew. Chem. Int. Ed. 2004, 43, 4364.

30) The precursors 20 were generally prepared from the corresponding 2,6-diiodophenols $\mathbf{5 4}$ in five steps as shown below. The overall yields were fairly good [for example, $20 \alpha\left(\mathrm{R}^{1}=\mathrm{H}\right)$ was obtained in $62 \%$ overall yield].

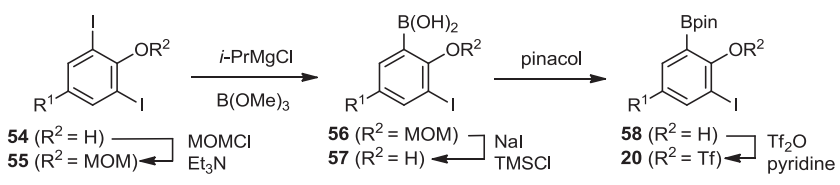

31) For the only example of a DA reaction of an unsymmetrically substituted benzyne with pyrrole, see: Gribble, G. W.; Kelly, W. J. Tetrahe- 
dron Lett. 1985, 26, 3779.

32) (a) Joule, J. A.; Mills, K. Heterocyclic Chemistry, 4th ed.; Blackwell, 2000. (b) Katrizky, A. R.; Pozharskii, A. F. Handbook of Heterocyclic Chemistry, 2nd ed.; Pergamon, 2000. (c) Eicher, T.; Hauptmann, S. The Chemistry of Heterocycles; Wiley-VCH, 2003.

33) For selected examples for [3+2] cycloaddition of benzynes: (a) Jin, T.; Yamamoto, Y. Angew. Chem. Int. Ed. 2007, 46, 3323. (b) Spiteri, C.; Keeling, S.; Moses, J. E. Org. Lett. 2010, 12, 3368. (c) Shi, F.; Waldo, J. P.; Chen, Y.; Larock, R. C. Org. Lett. 2008, 10, 2409. (d) Zhang, F. Z.; Moses, J. E. Org. Lett. 2009, 11, 1587. (e) Lu, C.; Dubrovskiy, A. V.; Larock, R. C. J. Org. Chem. 2012, 77, 2279. (f) Hong, D.; Chen, Z. B.; Lin, X. F.; Wang, Y. G. Org. Lett. 2010, 12, 4608. (g) McAusland, D.; Seo, S.; Pintori, D. G.; Finlayson, J.; Greaney, M. F. Org. Lett. 2011, 13,3667 .

34) The reaction of 3-silylbenzynes $\mathbf{7 A}$ with nitrones $\mathbf{3 6}$, which had been reported by Suzuki ${ }^{11}$ and Danishefsky under harsh reaction conditions, also gave benzisoxazoles 39A with high selectivity, see: Dai, M.; Wang, Z.; Danishefsky, S. J. Tetrahedron Lett. 2008, 49, 6613.

35) (a) Prous, J.; Grant, J.; Castaner, J. Drug Future 1994, 457. (b) Wood, P. M.; Lawrence, W., L. W.; Thomas, M. P.; Mahon, M. F.; Purohit, A.; Potter, B. V. L. ChemMedChem 2011, 6, 1423.

36) Gaussian 09, Revision B. 01, Frisch, M. J.; Trucks, G. W.; Schlegel, H. B.; Scuseria, G. E.; Robb, M. A.; Cheeseman, J. R.; Scalmani, G.; Barone, V.; Mennucci, B.; Petersson, G. A.; Nakatsuji, H.; Caricato, M.; Li, X.; Hratchian, H. P.; Izmaylov, A. F.; Bloino, J.; Zheng, G.; Sonnenberg, J. L.; Hada, M.; Ehara, M.; Toyota, K.; Fukuda, R.; Hasegawa, J.; Ishida, M.; Nakajima, T.; Honda, Y.; Kitao, O.; Nakai, H.; Vreven, T.; Montgomery, Jr., J. A.; Peralta, J. E.; Ogliaro, F.; Bearpark, M.; Heyd, J. J.; Brothers, E.; Kudin, K. N.; Staroverov, V. N.; Kobayashi, R.; Normand, J.; Raghavachari, K.; Rendell, A.; Burant, J. C.; Iyengar, S. S.; Tomasi, J.; Cossi, M.; Rega, N.; Millam, J. M.; Klene, M.; Knox, J. E.; Cross, J. B.; Bakken, V.; Adamo, C.; Jaramillo, J.; Gomperts, R.; Stratmann, R. E.; Yazyev, O.; Austin, A. J.; Cammi, R.; Pomelli, C.; Ochterski, J. W.; Martin, R. L.; Morokuma, K.; Zakrzewski, V. G.; Voth, G. A.; Salvador, P.; Dannenberg, J. J.; Dapprich, S.; Daniels, A. D.; Farkas, Ö.; Foresman, J. B.; Ortiz, J. V.; Cioslowski, J.; Fox, D. J. Gaussian, Inc., Wallingford CT, 2010.

37) (a) Wiberg, K. B. Tetrahedron 1968, 24, 1083. (b) Foster, J. P.; Weinhold, F. J. Am. Chem. Soc. 1980, 102, 7211. (c) Reed, A. E.; Weinstock, R. B.; Weinhold, F. J. Chem. Phys. 1985, 83, 735.

38) NBO 5.0, Glendening, E. D.; Badenhoop, J, K.; Reed, A. E.; Carpenter, J. E.; Bohmann, J. A.; Morales, C. M.; Weinhold, F. Theoretical Chemistry Institute, University of Wisconsin, Madison WI, 2001

39) Hamura, T.; Ibusuki, Y.; Sato, K.; Matsumoto, T.; Osamura, Y.; Suzuki, K. Org. Lett. 2003, 5, 3551.

40) Optimized structures of reactants, TSs, and products were characterized by analytical frequency calculations, and all total electronic energies of these species were included in the zero-point energy corrections at the same level. The calculated number of imaginary frequencies (NImag) determine whether the optimized structures are energy minima $(\mathrm{NImag}=0)$ or $\mathrm{TSs}(\mathrm{NImag}=1)$ along the reaction pathway.

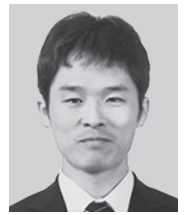

Takashi Ikawa is an Assistant Professor at the University of Shizuoka. He was born in Gifu, Japan, in 1977, and he received a Ph.D. degree (2005) from Gifu Pharmaceutical University. After two years of postdoctoral work (2005-2007) for Professor Stephen L. Buchwald at Massachusetts Institute of Technology, he joined the University of Shizuoka as an Assistant Professor in 2007. He received the Japanese Society for Process Chemistry Award for Excellence (2003) and the Daicel Chemical Industries, Ltd. Award in Synthetic Organic Chemistry, Japan (2008). His research interests are in the area of synthetic organic chemistry, organometallic chemistry, medicinal, and bioorganic chemistry.

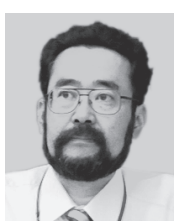

Hiroaki Tokiwa is a Professor at Rikkyo (St. Paul's) University. He received his A. B. degree (1985) from Shizuoka College of Pharmacy, and obtained a Ph.D. degree (1994) from Tohoku University. His academic career started at Hoshi College of Pharmacy in 1989, after which he moved to Rikkyo University in 1994 as a full-time lecturer. In 2000, he was promoted to the rank of Associated Professor at Rikkyo University and he was appointed as Full Professor at the same University in 2008. During his research career, he was a visiting researcher at Emory University (Atlanta, Prof. Keiji Morokuma, 1994, 1997, and 2006). His research interests are in the area of theoretical medicinal chemistry and in silico drug design based on first-principles calculations.

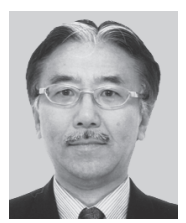

Shuji Akai obtained a Ph.D. degree (1987) from Osaka University. After two years of postdoctoral work as a JSPS Research Fellow at Osaka University, he was appointed Assistant Professor and promoted to Associate Professor (2005) at Osaka University. For one year (1997-1998), he was a Visiting Research Fellow with Professor Stephen L. Buchwald at MIT. In 2005, he was appointed Full Professor at the University of Shizuoka. He received the Inoue Research Award for Young Scientists (1987), the Pharmaceutical Society of Japan Award for Divisional Scientific Promotions (2003), and the Japanese Society for Process Chemistry Award for Excellence (2005 and 2011). His current research interests are in the area of synthetic organic chemistry, fluorine chemistry, medicinal chemistry, and enzymatic synthesis. 